\title{
C2238/aANP modulates apolipoprotein E through Egr-1/miR199a in vascular smooth muscle cells in vitro
}

\author{
R Stanzione ${ }^{1,4}$, S Sciarretta ${ }^{1,2,4}$, S Marchitti ${ }^{1}$, F Bianchi ${ }^{1}$, S Di Castro ${ }^{1}$, S Scarpino ${ }^{3}$, M Cotugno $^{1}$, G Frati ${ }^{1,2}$, M Volpe ${ }^{1,3}$ and S Rubattu*,1,3
}

Subjects carrying the T2238C ANP gene variant have a higher risk to suffer a stroke or myocardial infarction. The mechanisms through which $\mathrm{T} 2238 \mathrm{C} / \alpha \mathrm{ANP}$ exerts detrimental vascular effects need to be fully clarified. In the present work we aimed at exploring the impact of C2238/ $\alpha$ ANP (mutant form) on atherosclerosis-related pathways. As a first step, an atherosclerosis gene expression macroarray analysis was performed in vascular smooth muscle cells (VSMCs) exposed to either T2238/ $\alpha$ ANP (wild type) or C2238/ $\alpha$ ANP. The major finding was that apolipoprotein $E$ (ApoE) gene expression was significantly downregulated by C2238/ $\alpha$ ANP and it was upregulated by T2238/ $\alpha$ ANP. We subsequently found that C2238/ $\alpha$ ANP induces ApoE downregulation through type C natriuretic peptide receptor (NPR-C)-dependent mechanisms involving the upregulation of miR199a-3p and miR199a-5p and the downregulation of DNAJA4. In fact, NPR-C knockdown rescued ApoE level. Upregulation of miR199a by NPR-C was mediated by a reactive oxygen species-dependent increase of the early growth response protein-1 (Egr-1) transcription factor. In fact, Egr-1 knockdown abolished the impact of C2238/ $\alpha$ ANP on ApoE and miR199a. Of note, downregulation of ApoE by C2238/ $\alpha$ ANP was associated with a significant increase in inflammation, apoptosis and necrosis that was completely rescued by the exogenous administration of recombinant ApoE. In conclusion, our study dissected a novel mechanism of vascular damage exerted by C2238/ $\alpha$ ANP that is mediated by ApoE downregulation. We provide the first demonstration that C2238/ $\alpha$ ANP downregulates ApoE in VSMCs through NPR-C-dependent activation of Egr-1 and the consequent upregulation of miR199a. Restoring ApoE levels could represent a potential therapeutic strategy to counteract the harmful effects of C2238/ $\alpha$ ANP.

Cell Death and Disease (2015) 6, e2033; doi:10.1038/cddis.2015.370; published online 31 December 2015

Atrial natriuretic peptide (ANP) plays important cytoprotective cardiovascular functions, such as antihypertrophic, antiproliferative and prosurvival effects in cardiomyocytes, vascular smooth muscle cells (VSMCs), fibroblasts and endothelial cells. ${ }^{1}$ Recent work demonstrated that a molecular variant of aANP (C2238/aANP), which is characterized by the C-terminal extension of the peptide with two arginine residues and is secondary to the substitution of a thymine for a cytosine at position 2238 of the ANP gene, exerts detrimental vascular effects. In fact, we and other groups previously showed that subjects carrying the T2238C ANP gene variant have a significantly higher risk to have a stroke or a myocardial infarction and display a significant increase of circulating markers of leukocyte activation. ${ }^{2-8}$ Overall, this evidence highlights the need to find therapeutic targets to prevent or reduce the detrimental effects of C2238/aANP gene variant, which is relatively frequent in the general population. However, this is possible only if the molecular mechanisms through which C2238/aANP favors the development of vascular dysfunction, atherosclerosis and cardiovascular accidents are fully elucidated.

We previously reported that C2238/aANP molecular variant promotes cellular apoptosis, necrosis and oxidative stress, whereas it reduces cell proliferation, angiogenesis and vasodilation. ${ }^{9-11}$ Mechanistically, we found that the deleterious effects of C2238/aANP variant are mediated by a deregulated activation of the type $C$ natriuretic peptide receptor (NPR-C) with a consequent decrease of cAMP levels and PKA activity. ${ }^{10,11}$ The abnormal activation of NPR-C was found to be associated with a reduction of the Akt/eNOS pathway and an increase in NADPH oxidase-derived reactive oxygen species (ROS) activity in endothelial cells. ${ }^{9,10}$ In addition, an epigenetic phenomenon involving miR21 significantly contributed to the detrimental effects of C2238C/ aANP on cell viability and function in VSMCs. ${ }^{11}$ However, these molecular mechanisms can only explain the deleterious properties of C2238/aANP on atherosclerotic plaque stability. On the other hand, the interaction of C2238/aANP with

\footnotetext{
${ }^{1}$ IRCCS Neuromed, Pozzilli (Is), Sapienza University of Rome, Latina, Italy; ${ }^{2}$ Department of Medical-Surgical Sciences and Biotechnologies, Sapienza University of Rome, Latina, Italy and ${ }^{3}$ Department of Clinical and Molecular Medicine, School of Medicine and Psychology, Sapienza University of Rome, Ospedale S. Andrea, Rome, Italy ${ }^{*}$ Corresponding author: S Rubattu, Clinical and Molecular Medicine Department, School of Medicine and Psychology, Sapienza University, S. Andrea Hospital, Rome; IRCCS Neuromed, Pozzilli (Is), Rome 00189, Italy. Tel: +39 06 33775979; Fax: +39 06 33775061; E-mail: rubattu.speranza@ neuromed.it

${ }^{4}$ These authors contributed equally to this work.

Abbreviations: Akt, protein kinase B; ApoE, apolipoprotein E; ANP, atrial natriuretic peptide; TT2238/ $\alpha$ ANP, wild-type atrial natriuretic peptide at pos. 2238; CC2238/ $\alpha A N P$, mutant atrial natriuretic peptide at pos. 2238; CAMP, cyclic adenosine monophosphate; CREG, cellular repressor of E1A-stimulated gene; CREB, cAMP responsive element binding protein; DNAJA4, DnaJ (Hsp40) homolog; Egr-1, early growth response protein-1; eNOS, endothelial nitric oxide synthase; EDTA, ethylenediaminetetracetic acid; FOXO4, forkhead box 04; FACS, flow cytometry analysis; JNK, c-Jun N-terminal kinase; miRNA, microRNA; NADPH, nicotinamide adenine dinucleotide phosphate-oxidase; Nf- $\kappa B$, nuclear factor kappa-light chain-enhancer of activated B cells; NPR-C, type C natriuretic peptide receptor; NPR-A, type A natriuretic peptide receptor; PKA, protein kinase A; ROS, reactive oxygen species; RT-PCR, real time-polymerase chain reaction; Smad4, mothers against decapentaplegic Homolog 4; TGF, tumor growth factor; VSMC, vascular smooth muscle cell; HUVSMC, human umbilical vein smooth muscle cell; CASMC, coronary artery smooth muscle cell

Received 08.9.15; revised 16.11.15; accepted 17.11.15; Edited by A Stephanou
} 
Table 1 Atherosclerosis genes that are modulated by TT2238/aANP and CC2238/aANP versus control according to real time-PCR array

\begin{tabular}{lcc}
\hline Gene name & $\begin{array}{c}\text { TT2238/aANP versus } \\
\text { Ctrl }\end{array}$ & $\begin{array}{c}\text { CC2238/aANP versus } \\
\text { Ctrl }\end{array}$ \\
\hline APOE & $38.48 \pm 18.57$ & $-6.66 \pm 4.13$ \\
BCL2 & $9.37 \pm 3.84$ & $-6.70 \pm 1.94$ \\
BCL2A1 & $16.62 \pm 39.98$ & $-1.13 \pm 1$ \\
BCL2L1 & $24.24 \pm 14.69$ & $133.34 \pm 79.02$ \\
CCL2 & $-736.48 \pm 426.11$ & $-5514.23 \pm 2765.44$ \\
CTGF & $-1.89 \pm 1$ & $-12.14 \pm 15.01$ \\
FGF2 & $-40.18 \pm 19.21$ & $0.29 \pm 3.78$ \\
FN1 & $-1855.62 \pm 888.82$ & $-0.97 \pm 2.57$ \\
ITGA2 & $2.70 \pm 3.32$ & $18.22 \pm 7.09$ \\
ITGA5 & $-0.95 \pm 5.45$ & $-20.05 \pm 7.52$ \\
MMP3 & $10.57 \pm 7.79$ & $21.57 \pm 14.94$ \\
NOS3 & $-24.76 \pm 1$ & $-2.51 \pm 1$ \\
PDGFB & $8.07 \pm 4.96$ & $0.04 \pm 2.52$ \\
PPARD & $-6.05 \pm 1.87$ & $-0.93 \pm 1.94$ \\
PPARG & $-7.16 \pm 1.36$ & $-4,57 \pm 0,33$ \\
SERPINE1 & $-2.61 \pm 2.55$ & $-5.84 \pm 0,67$ \\
SOD1 & $-4.77 \pm 7.16$ & $1.22 \pm 3.20$ \\
TNC & $-109.95 \pm 63.82$ & $-1.80 \pm 2.52$ \\
TNF & $6.04 \pm 5.03$ & $-2.59 \pm 6.53$ \\
& &
\end{tabular}

Number of independent experiments $=3$.

$B C L 2$, B-cell lymphoma 2; CCL2, chemokine ligand 2; CTGF, connective tissue growth factor; FGF2, fibroblast growth factor 2; FN1, fibronectin 1; ITGA2, integrin alpha 2; ITGA5, integrin alpha 5; MMP3, matrix metallopeptidase 3; NOS3, nitric oxide synthase 3; PDGFB, platelet-derived growth factor subunit $\mathrm{B}$; $P P A R D, P P A R G$, peroxisome proiliferator-activated receptor delta, gamma; SERPINE1, serpin peptidase inhibitor; SOD1, superoxide dismutase 1; TNF, tumor necrosis factor.

multiple genes/proteins directly related to the atherosclerotic process remains unknown. This latter possibility is supported by the known involvement of natriuretic peptides in atherosclerosis. $^{1}$

For this reason, we conducted a gene expression macroarray analysis in VSMCs, a key cellular element in atherosclerosis development ${ }^{12}$ and a target of $A N P,{ }^{1}$ in order to investigate the potential impact of T2238C/aANP on mechanisms underlying atherosclerosis. We found that C2238/aANP induces a significant downregulation of the apolipoprotein $\mathrm{E}$ $(A p o E)$ gene expression, encoding a known antiatherosclerotic and anti-inflammatory protein, through the activation of the NPR-C/Egr-1/miR199a/DNAJA4 signaling pathway that we dissect here for the first time. ApoE downregulation was found to be responsible for the detrimental cellular abnormalities induced by T2238C/aANP in VSMCs.

\section{Results}

Differential ApoE gene expression in VSMCs induced by TT2238/aANP and CC2238/aANP. Atherosclerosis genes expression profile of human umbilical vein smooth muscle cells (HUVSMCs) exposed to either TT2238/aANP or CC2238/aANP, compared with unstimulated cells, is reported in Table 1. Among the sequences that were significantly and differentially regulated (at least 5-fold) by the two aANP forms, ApoE gene was significantly reduced by CC2238/ aANP, whereas it was markedly stimulated by TT2238/aANP. We validated the macroarray results by demonstrating that both ApoE mRNA and protein expression levels were downregulated in both HUVSMCs (Figures 1a and b) and coronary artery SMCs (CAMSCs) (Figures 1c and d)

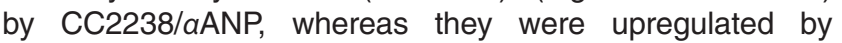
TT2238/aANP. Since it is well known that ApoE exerts critical antiatherosclerotic and anti-inflammatory actions, ${ }^{13}$ we decided to evaluate whether ApoE downregulation mediates the detrimental effects of CC2238/aANP.

CC2238/aANP induces ApoE downregulation through NPR-C-dependent mechanisms associated with the upregulation of miR199a. We then dissected the mechanisms through which CC2238/aANP induces the reduction of ApoE expression. Previous work from our laboratory demonstrated that CC2238/aANP induces detrimental vascular effects through a deregulated activation of NPR-C. ${ }^{10,11}$ Therefore, we investigated whether NPR-C mediates the effects of CC2238/aANP on ApoE expression levels. Our results confirmed this hypothesis, since we found that NPR-C knockdown rescued ApoE expression levels in both HUVSMCs and coronary artery smooth muscle cells (CASMCs) exposed to CC2238/aANP (Figures 2a and $3 a)$.

Of note, previous evidence demonstrated that ApoE expression levels are epigenetically regulated by miR199a$3 p$ and miR199a-5p, which in turn can either directly target ApoE or target the heat-shock protein DNAJA4, which promotes the upregulation of ApoE. ${ }^{14}$ In line with this evidence, we found that miR199a-3p and miR199a-5p expression levels are significantly upregulated by CC2238/aANP, whereas they are downregulated by TT2238/aANP. On the other hand, the DNAJA4 expression level resulted to be downregulated by CC2238/aANP, whereas it was unchanged in cells exposed to TT2238/aANP (Figures $2 b$ and 3b). Interestingly, we observed that NPR-C knockdown rescued miR199a-3p, miR199a-5p and DNAJA4 expression levels in both VSMC lines treated with CC2238/aANP (Figures $2 b$ and $3 b$ ). These data suggest that NPR-C regulates ApoE levels through the regulation of miR199a-3p, miR199a-5p and DNAJA4.

NPR-C regulates miR199a through the ROS-dependent activation of early growth response protein-1 (Egr-1). Then, we tried to elucidate the signaling mechanisms through which NPR-C promotes the upregulation of miR199a-3p and miR199a-5p, the downregulation of DNAJA4 and ultimately the downregulation of ApoE expression levels in response to CC2238/aANP. The transcription factor Egr-1 was previously found to promote the upregulation of miR199a. ${ }^{15}$ In addition, Egr-1 is often found activated in the vasculature during stress and was described to be involved in the atherosclerotic process. ${ }^{16}$ Therefore, we evaluated whether Egr-1 is involved in the NPR-C-dependent regulation of miR199a-3p and miR199a-5p in response to CC2238/ aANP. We found that Egr-1 is upregulated in response to CC2238/aANP and this effect was abrogated by NPR-C knockdown (Figures $2 \mathrm{c}$ and $3 \mathrm{c}$ ). CC2238/aANP is known to induce NPR-C-dependent NADPH oxidase activation and ROS production. ${ }^{9,10}$ Egr-1 can be activated by ROS. ${ }^{17}$ In accordance, we found that C2238/aANP-dependent upregulation of Egr-1 was blunted by apocynin, a NADPH oxidase inhibitor (Supplementary Figure S1). Finally, we found that Egr-1 knockdown normalized miR199a and DNAJA4 levels 

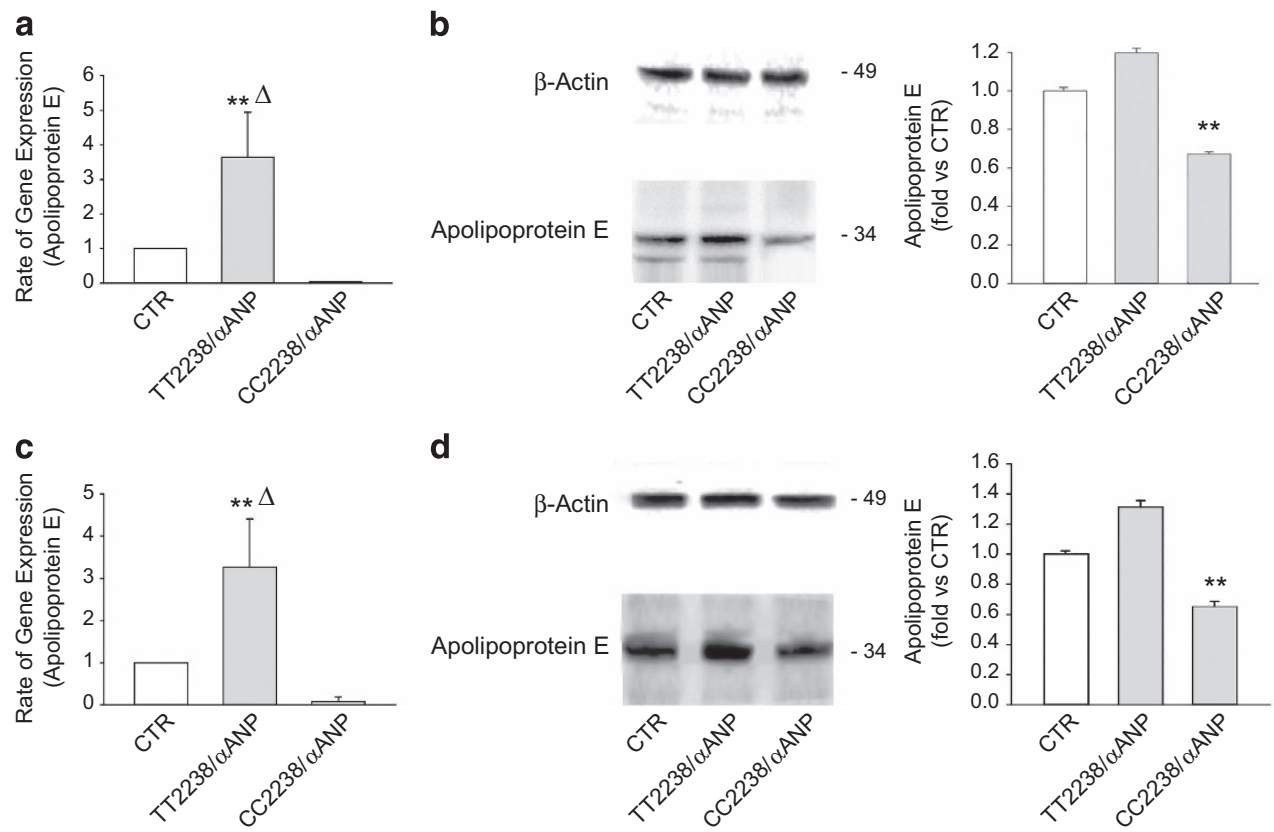

Figure 1 Differential regulation of ApoE mRNA and protein levels by TT2238/ $\alpha$ ANP and CC2238/ $\alpha$ ANP in HUVSMCs and CAMSCs. Results of RT-PCR (a and $\mathbf{c}$ ) and of western blotting (b and $\mathbf{d}$, with corresponding densitometric analysis) for ApoE expression levels in HUVSMCs (upper part) and in CASMCs (lower part). Results are expressed as mean \pm S.D. Number of independent experiments $=6 . \Delta P<0.005$ for TT2238/ $\alpha$ ANP versus $\mathrm{CTR} .{ }^{*} P<0.0001$ for TT2238/ $\alpha$ ANP versus $\mathrm{CC} 2238 / \alpha \mathrm{ANP}$ (a and $\left.\mathbf{b}\right)$ and for CC2238/ $\alpha$ ANP versus both CTR and TT2238/ $\alpha$ ANP ( $b$ and $\mathbf{d}$ ). CC2238/ $\alpha$ ANP, variant $\alpha$ ANP; TT2238/ $\alpha$ ANP, wild-type $\alpha$ ANP; CTR, control

and blocked the ApoE downregulation in both VSMC lines treated with CC2238/aANP (Figure 4). Overall, these data indicate that CC2238/aANP leads to miR199a upregulation and ApoE downregulation in VSMCs through the NPR-Cdependent ROS production which in turn leads to Egr-1 activation.

CC2238/aANP modulates apoptosis, necrosis and inflammation in VSMCs through NPR-C-dependent ApoE downregulation. Then, we evaluated the biological significance of ApoE downregulation in cells exposed to CC2238/ aANP. Supplementary Figures S2 and S3 show the results of western blotting analysis to evaluate the expression levels of cleaved caspase-3, cellular repressor of E1A-stimulated gene (CREG), and both phosphorylated and total forms of JNK and p38MAPK in HUVSMCs (Supplementary Figure S2) and in CASMCs (Supplementary Figure S3) in the presence of CC2238/aANP. Cleaved caspase-3 was increased by CC2238/aANP (Supplementary Figures S2A and S3A). On the other hand, expression of CREG, an antiapoptotic factor, was reduced (Supplementary Figures S2B and S3B). Consistently with previous studies showing that CREG inhibits VSMC apoptosis through the inhibition of p38MAPK and JNK signaling pathways, ${ }^{18}$ we observed a parallel increased phosphorylation of both p38MAPK and JNK in both HUVSMCs and CASMCs treated with CC2238/aANP as compared with control cells (Supplementary Figures S2C, D, $\mathrm{S} 3 \mathrm{C}$ and $\mathrm{D}$ ). Of note, NPR-C knockdown completely rescued the CC2238/aANP effects on cleaved-caspase-3, phosphop38MAPK, phosphoJNK and CREG. Cellular levels of NF- $K$ B and Smad4, known markers of inflammation, were also significantly increased in both HUVSMCs and CASMCs exposed to CC2238/aANP (Supplementary Figures S2E, F, $\mathrm{S} 3 \mathrm{E}$ and $\mathrm{F}$ ). NPR-C gene silencing blunted the increase of both NF- $k$ B and Smad4 despite the presence of CC2238/ aANP in both VSMC lines (Supplementary Figures S2E, F, S3E and F). Altogether, these findings indicate that C2238/ aANP induces apoptosis and inflammation in VSMCs through NPR-C-dependent mechanisms.

Of note, we found that these mechanisms are mediated by ApoE downregulation. First of all, sequencing analysis revealed that HUVSMCs express the ApoE isoforms 2 and 3 (APOE2/APOE3) whereas CASMCs express ApoE isoforms 3 and 4 (APOE3/APOE4) (Supplementary Figure 4). More importantly, we found that restoration of ApoE levels in both HUVSMCs (Figure 5a) and CASMCs (Figure 5b) treated with CC2238/aANP through the concomitant exogenous administration of the corresponding ApoE recombinant isoform was able to rescue cell viability, which was significantly impaired by CC2238/aANP alone as compared with untreated cells. ApoE administration significantly reduced both early and late apoptosis and necrosis induced by CC2238/aANP. In addition, VSMCs showed a significant decrease of inflammation under exposure to recombinant ApoE despite the presence of CC2238/aANP (Figure 6).

\section{Discussion}

T2238C/aANP gene variant is an emerging non-modifiable cardiovascular risk factor. In fact, subjects carrying this genetic variant have a higher risk for occurrence of cardiovascular adverse events, such as stroke and myocardial infarction. In 
addition, these subjects display signs of endothelial dysfunction already at a young age. Here, we analyzed the impact of the T2238C/aANP gene variant on atherosclerosis-related mechanisms. We found that C2238/aANP significantly downregulates $A p o E$ gene expression in VSMCs through NPR-C-dependent mechanisms. We also demonstrated that

a
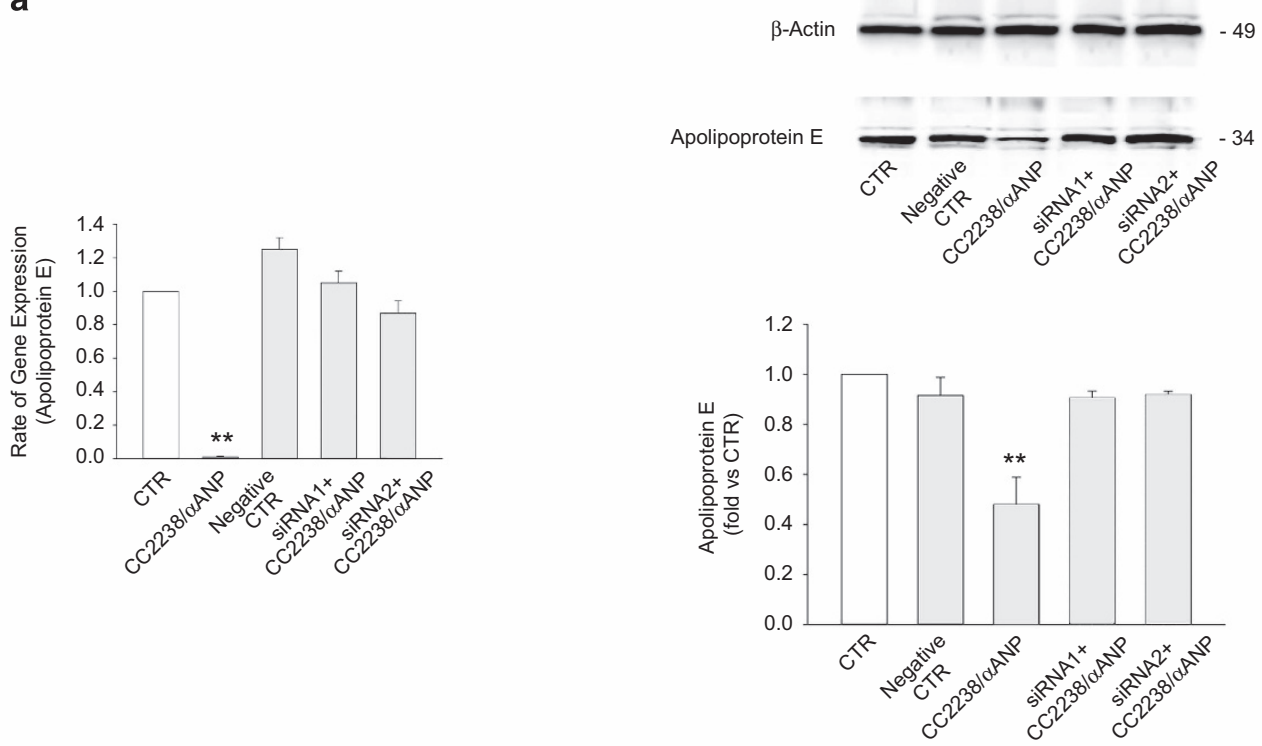

b
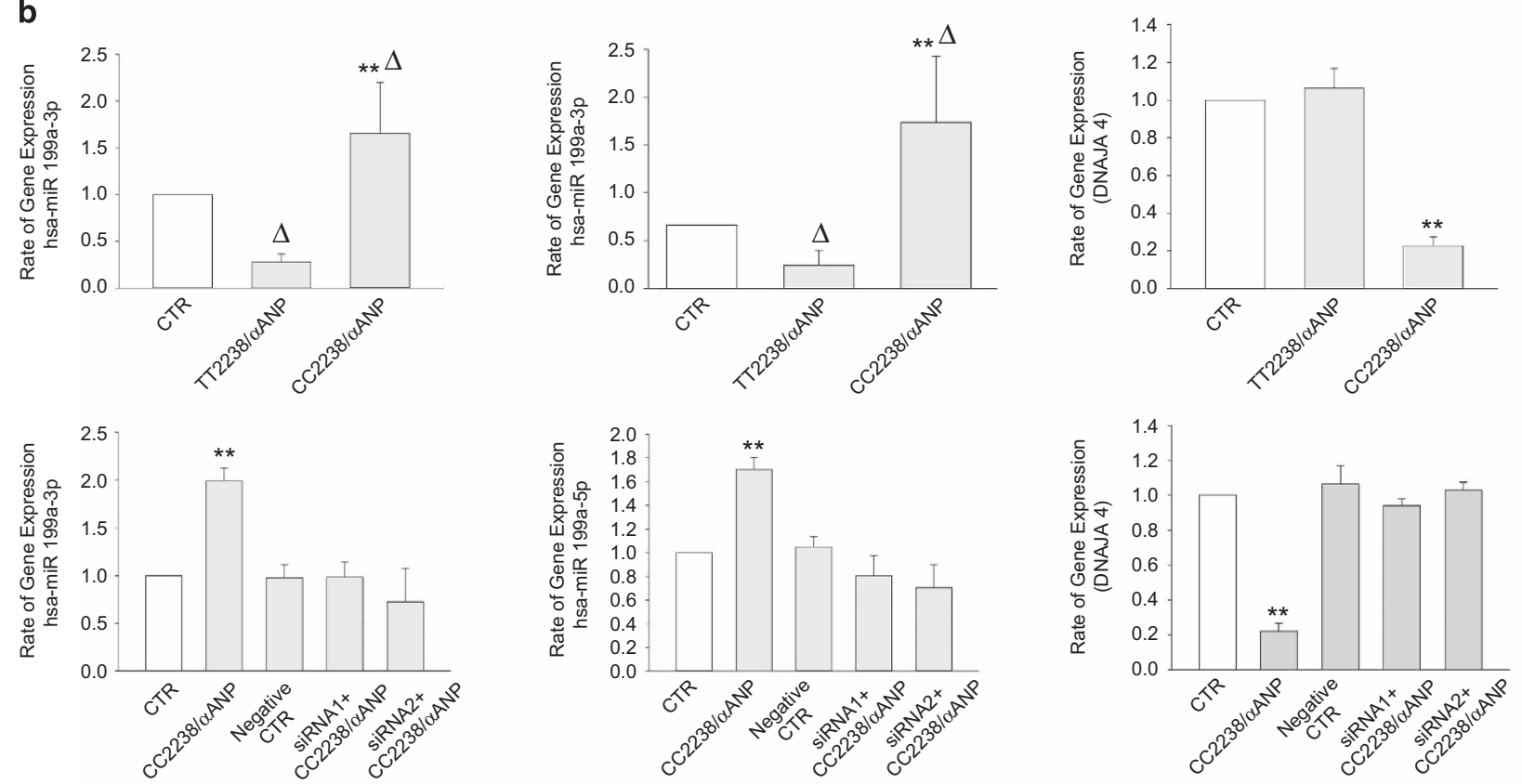

c
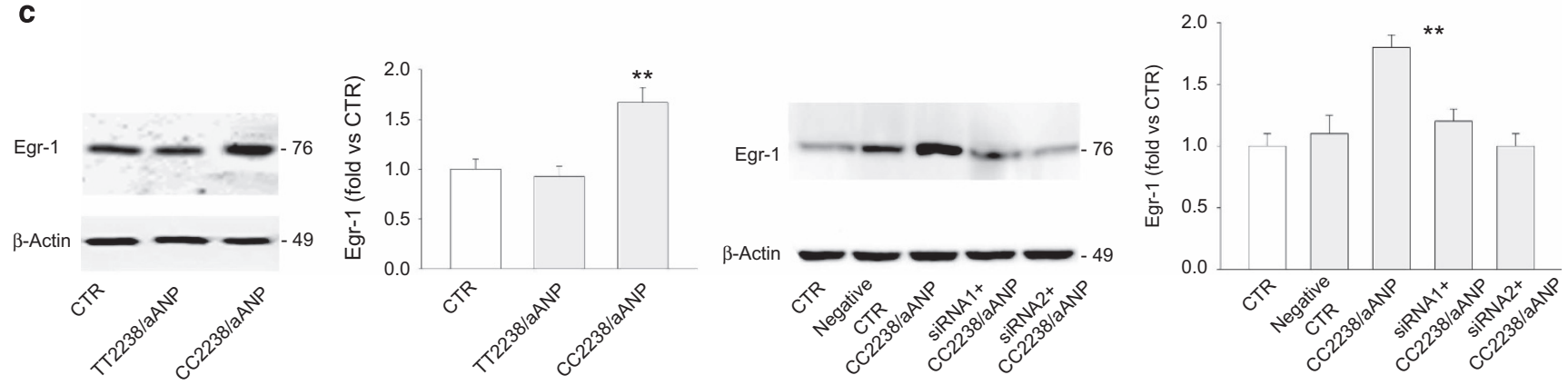
C2238/aANP plays this effect through a selective epigenetic regulation of ApoE involving Egr-1 and two small noncoding RNAs (miR199a-3p and miR199a-5p). Most importantly, we provided evidence that the detrimental effects induced by the C2238/aANP-NPR-C axis in VSMCs, such as increased rate of apoptosis, necrosis and inflammation, could be fully recovered by recombinant $\mathrm{ApoE}$ protein supplementation (Figure 7).

These data significantly extend our previous evidence demonstrating that C2238/aANP induces endothelial cell death and oxidative stress, reduces angiogenesis and promotes endothelial dysfunction through the deregulated activation of NPR-C/cAMP signaling and the reduction of the PKA/ Akt/eNOS pathway. ${ }^{9-10}$ In addition, we recently found that C2238/aANP increases oxidative stress and cellular migration and promotes vasoconstriction through the NPR-C/cAMP/ PKA/CREB/miR21 signaling pathway. ${ }^{11}$ The current study demonstrates for the first time a direct impact of C2238/aANP on mechanisms underlying atherosclerosis in VSMCs, a key element in this process. In fact, C2238/aANP induces a significant downregulation of ApoE which plays an important role on atherosclerosis development. ${ }^{19,20}$ ApoE is a 34-kDa protein that participates in the mobilization and distribution of cholesterol and of other lipids among various tissues of the body. ${ }^{20}$ It is known that ApoE deficiency alone promotes the development of aortic atherosclerotic plaques in mice. ${ }^{21}$ Previous studies demonstrated that ApoE exerts also pleiotropic antiatherosclerotic and anti-inflammatory cellular effects. ApoE was previously found to be expressed in VSMCs where ApoE downregulation is positively correlated with typical markers of inflammation such as Smad4 ${ }^{22}$ and NF- $K$ $B .^{23}$ In addition, ApoE hampers the proinflammatory functions of inflammatory cells. ${ }^{24}$ In humans, where lack of ApoE is rare, risk of atherosclerosis is strongly associated with three common apoE isoforms in the order of APOE4 $>$ APOE3 $>$ APOE2. ${ }^{20}$ Furthermore, ApoE is known to play a role in the development of both cardiovascular ${ }^{25}$ and neurological diseases. ${ }^{26}$ Therefore, our study may suggest that C2238/ aANP induces cellular abnormalities through the inhibition of the above-described pleiotropic effects of ApoE. Furthermore, since higher myeloperoxidase levels were reported in $\mathrm{Apo}^{-/-}$ mice, ${ }^{27}$ we can postulate that C2238/aANP may, at least in part, associate to higher myeloperoxidase levels, as previously reported in coronary artery disease patients, ${ }^{4}$ through its ability to lower ApoE gene expression.

On the other hand, our current results indicate that wild-type aANP may exert physiological antiatherosclerotic effects by upregulating ApoE levels. This possibility is supported by previous evidence suggesting a close relationship between natriuretic peptides (NPs) and atherosclerosis. In fact, NPs are significantly more expressed in human coronary explants of advanced atherosclerotic lesions. ${ }^{28}$ Inhibition of NP degradation by NEP inhibitor candoxatril prevented fatty deposit in a rabbit model. ${ }^{29}$ Circulating NP levels increase in parallel to the increase of coronary plaque stenosis, reaching a plateau level at the highest degree of vessel stenosis. ${ }^{30}$

Notably, previous work has shown that atherosclerosis increases in an animal model lacking both NPR-A and ApoE $\left(\mathrm{Npr}^{-1-} \mathrm{ApoE}^{-/-}\right.$mice $){ }^{31}$ suggesting that lack of NPR-A could induce VSMC growth through other receptor signaling, thus enhancing the negative vascular effects due to lack of ApoE.

Another original finding of our study is the demonstration that $\mathrm{C} 2238 / a \mathrm{ANP}$ induces ApoE downregulation through the NPR-C-dependent upregulation of Egr-1. This effect is mediated by NADPH oxidase activity, since apocynin abrogated the effects of C2238/aANP on Egr-1 activation. To our knowledge, this is the first time that a negative epigenetic regulation of ApoE by Egr-1 is demonstrated in the vascular context. This finding also extends previous evidence advocating a role of Egr-1 activation in the development of atherosclerosis and may suggest that Egr-1 activation may contribute to atherosclerosis through the downregulation of ApoE. Interestingly, previous work demonstrated that atherosclerosis is reduced in a double knockout model of Egr-1 and ApoE mice, as compared with that observed in the $\mathrm{ApoE}^{-/-}$knockout model only, thus suggesting that lack of Egr-1 is protective in the absence of ApoE. ${ }^{32}$ Our study extends this evidence by demonstrating that Egr-1 can be upstream of ApoE, negatively regulating its expression.

Of note, we found that Egr-1 activation by C2238/aANP promotes the upregulation of miR199a-3p and miR199a-5p, thus confirming previous findings demonstrating that Egr-1 regulates miR199a. ${ }^{15}$ These data suggest that Egr-1 may epigenetically regulate ApoE through these two microRNAs (miRNAs). In fact, Pencheva et al. ${ }^{14}$ have recently demonstrated that miR199a-3p and miR199a-5p regulate melanoma metastasis formation through the downregulation of $\mathrm{ApoE}$ levels. The authors found that these miRNAs may either target ApoE directly or indirectly inhibit ApoE levels through the targeting of DNAJA4, a heat-shock protein stimulating ApoE levels. In line with this evidence, we also found that C2238/ aANP/NPR-C/Egr-1/miR199a signaling promotes the downregulation of DNAJA4 levels.

Of note, these findings reinforce available evidence elucidating the role of miRNAs in the pathogenesis of VSMC abnormalities and of vascular diseases in general. In this

\footnotetext{
Figure 2 C2238/ $\alpha$ ANP induces ApoE downregulation through NPR-C-dependent mechanisms associated with the upregulation of miR199a and of Egr-1 in HUVSMCs. (a) Analysis by RT-PCR and by western blotting of ApoE expression levels upon CC2238/ $\alpha$ ANP in NPR-C not silenced and silenced cells. ${ }^{* *} P<0.0001$ for CC2238/ $\alpha$ ANP versus all other samples. (b) miR199a-3p, miR199a-5p, DNAJA4 mRNA levels under either TT2238/ $\alpha$ ANP or CC2238/ $\alpha$ ANP (upper part of the panel) and in NPR-C not silenced and silenced cells under CC2238/ $\alpha$ ANP (lower part of the panel). Two specific siRNAs were used to obtain NPR-C gene silencing. ${ }^{*} P<0.0001$ for CC2238/ $\alpha$ ANP versus TT2238/ $\alpha$ ANP and CTR. $\Delta P<0.005$ for TT2238/ $\alpha$ ANP versus CTR and for CC2238/ $\alpha$ ANP versus CTR (miR199a-3p and miR199a-5p). (c) Representative western blotting of Egr-1, with corresponding densitometric analysis under either TT2238/ $\alpha$ ANP or CC2238/ $\alpha$ ANP exposure (left side) and under CC2238/ $\alpha$ ANP in NPR-C not silenced and silenced cells (right side). ${ }^{* \star} P<0.0001$ for CC2238/ $\alpha$ ANP versus all other samples. Results are expressed as mean \pm S.D. Number of independent experiments $=6$. CC2238/ $\alpha$ ANP, variant $\alpha$ ANP; TT2238/ $\alpha$ ANP, wild-type $\alpha$ ANP; siRNA1, NPR-C gene silencer 1; siRNA2, NPR-C gene silencer 2; hsa-miR199a, human microRNA199a; Egr-1, early growth response protein-1; CTR, control
} 
a

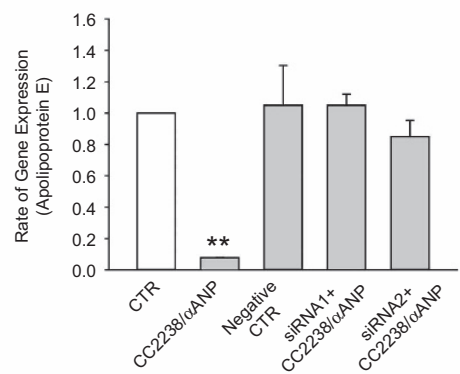

$\beta$-Actin --49
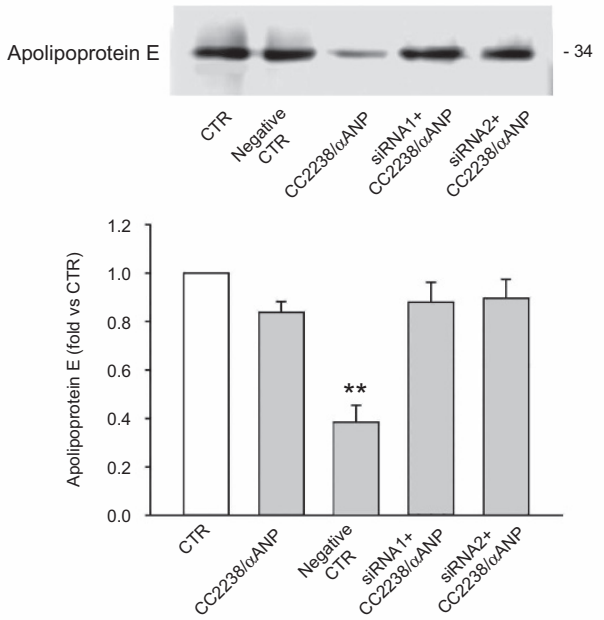

b
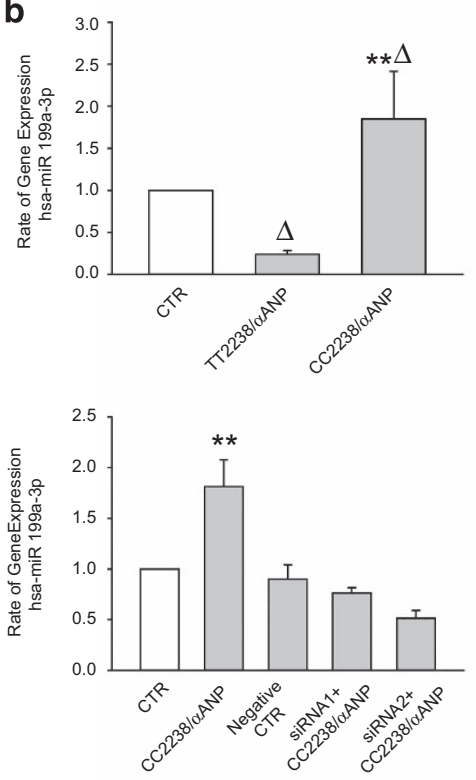
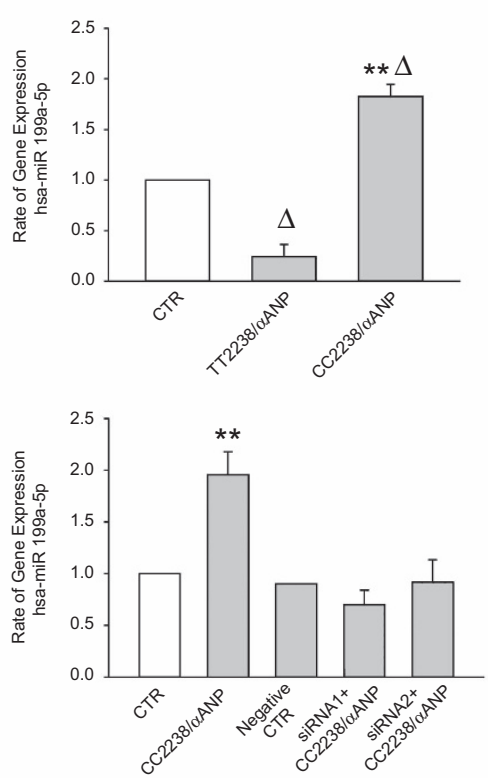
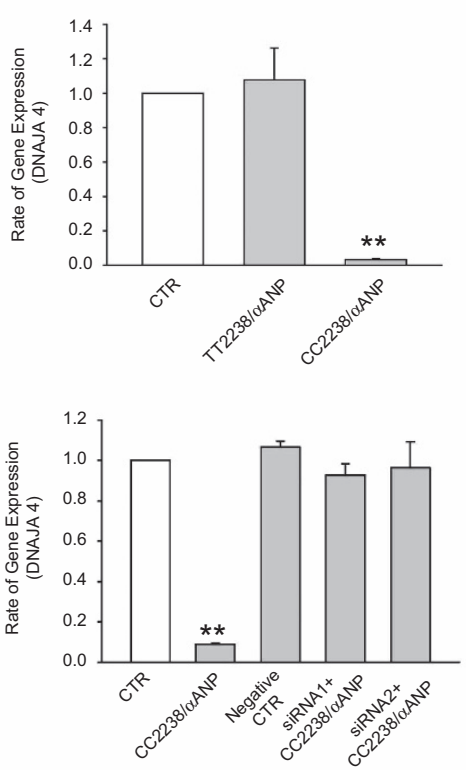

C
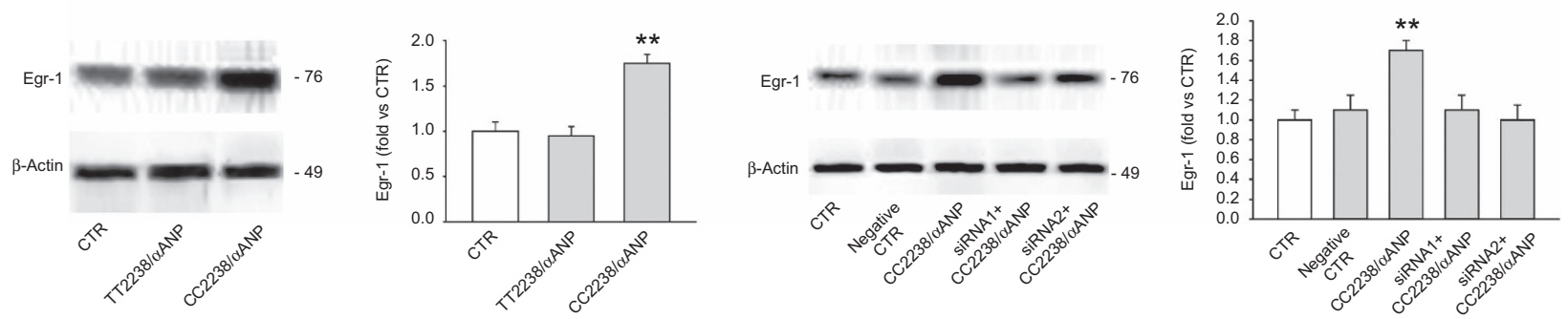

Figure $3 \mathrm{C} 2238 / \alpha$ ANP induces ApoE downregulation through NPR-C-dependent mechanisms associated with the upregulation of miR199a and of Egr-1 in CASMCs. (a) Analysis by RT-PCR and by western blotting of ApoE expression levels upon CC2238/ $\alpha$ ANP in NPR-C not silenced and silenced cells. ${ }^{* *} P<0.0001$ for CC2238/ $\alpha$ ANP versus all other samples. (b) miR199a-3p, miR199a-5p, DNAJA4 mRNA levels under either TT2238/ $\alpha$ ANP or CC2238/ $\alpha$ ANP (upper part of the panel) and in NPR-C not silenced and silenced cells under CC2238/ $\alpha$ ANP (lower part of the panel). Two specific siRNAs were used to obtain NPR-C gene silencing. ${ }^{* *} P<0.0001$ for CC2238/ $\alpha$ ANP versus TT2238/ $\alpha$ ANP and CTR. $\Delta P<0.005$ for TT2238/ $\alpha$ ANP versus CTR and for CC2238/ $\alpha$ ANP versus CTR (miR199a-3p and miR199a-5p). (c) Representative western blotting of Egr-1, with corresponding densitometric analysis under either TT2238/ $\alpha$ ANP or CC2238/ $\alpha$ ANP exposure (left side) and under CC2238/ $\alpha$ ANP in NPR-C not silenced and silenced cells (right side). ${ }^{* \star} P<0.0001$ for $C$ C2238/ $\alpha$ ANP versus all other samples. Results are expressed as mean \pm S.D. Number of independent experiments $=6$. For abbreviations see Figure 2 
a
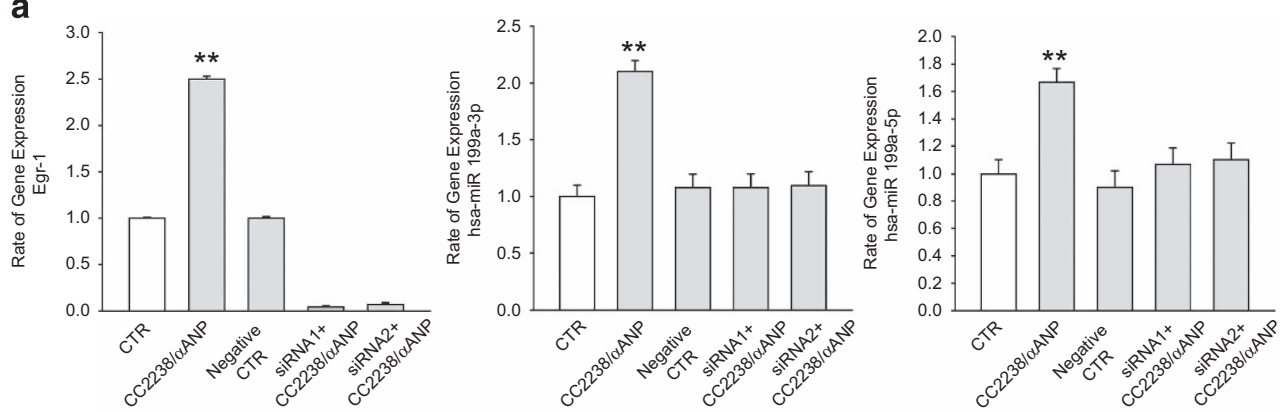
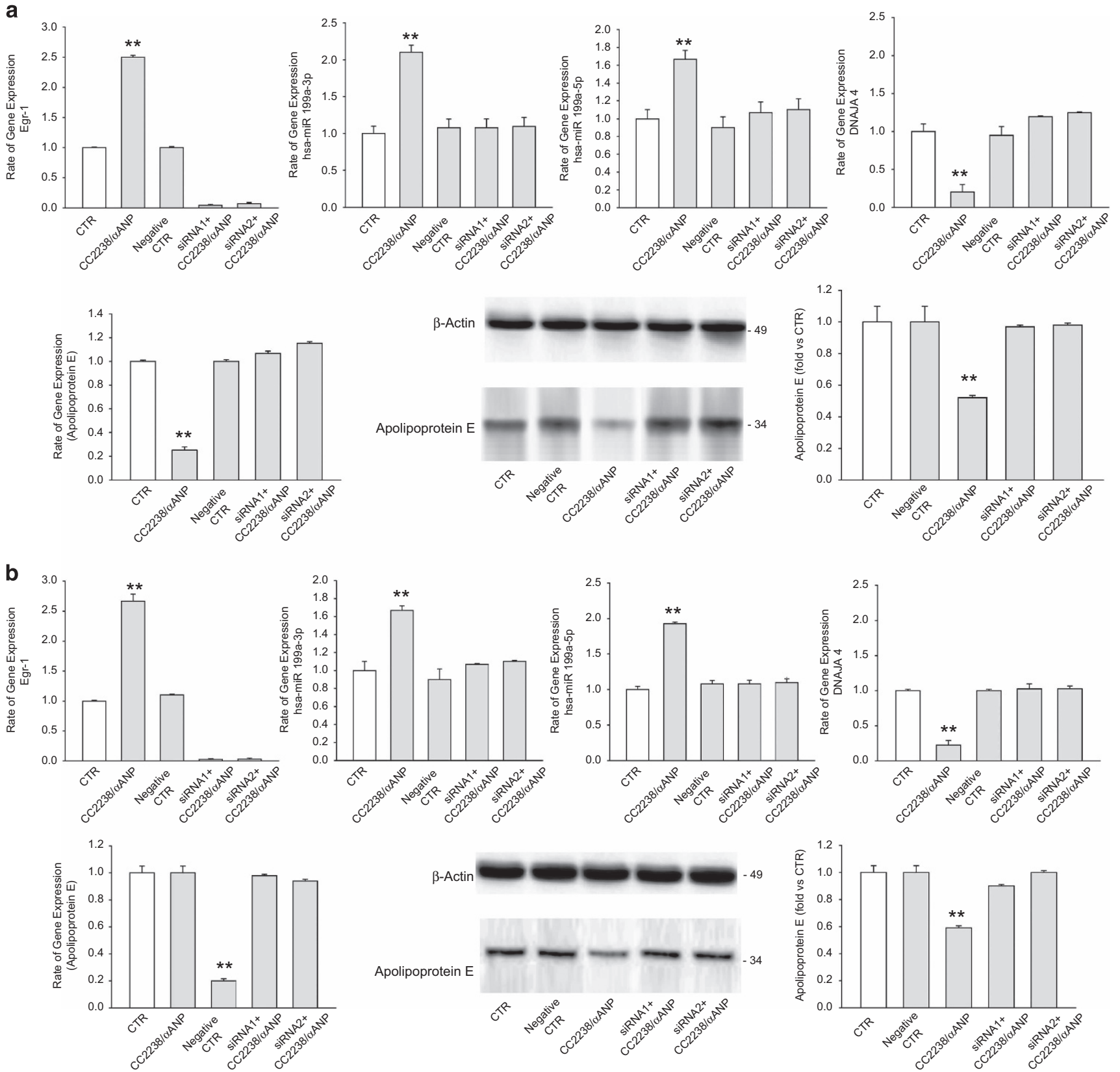

Figure 4 Impact of Egr-1 gene silencing on the ApoE regulatory pathway in both HUVSMCs and CAMSCs. (a) Impact of Egr-1 gene silencing on Egr-1, miR199-3p, miR1995p, DNAJA4 expression levels (as detected by RT-PCR) and on ApoE expression levels (as detected by both RT-PCR and western blotting) in HUVSMCs. Two specific siRNAs were used to obtain Egr-1 gene disruption. (b) Impact of Egr-1 gene silencing on Egr-1, miR199-3p, miR199-5p, DNAJA4 expression levels (as detected by RT-PCR), and on ApoE expression levels (as detected by both RT-PCR and western blot) in CASMCs. Results are expressed as mean \pm S.D. Number of independent experiments $=4$ for each cell lines. ${ }^{*} P<0.0001$ for CC2238/ $\alpha$ ANP versus all other points. siRNA1, Egr-1 gene silencer 1; siRNA2, Egr-1 gene silencer 2; for other abbreviations see Figures 2 and 3

regard, we previously found that a dysregulation of miR21 contributed to VSMC derangements upon C2238/aANP stimulation. ${ }^{11}$ In addition, downregulation of miR23b in injured vascular wall was recently found to modulate VSMC phenotypic switching through the involvement of both SMAD3 and FOXO4. ${ }^{33}$ Overall, this evidence supports the knowledge that miRNA-dependent epigenetic mechanisms can regulate the pathogenesis of human diseases in a highly integrative manner.
Previous deliveries of human ApoE3 by intramuscular plasmid injection and adenovirus, ${ }^{34}$ by synthetic apolipoprotein mimetic peptides ${ }^{35}$ or by a cell-based platform, ${ }^{36}$ have inhibited the development of atherosclerotic lesions. We first assessed the specific ApoE isoform expressed by the two VSMC lines used in our studies, which was never reported before. Consequently, we observed full benefits from the exposure of VSMCs to the specific recombinant ApoE isoform, despite the presence of C2238/aANP. The pleiotropic effects 
a
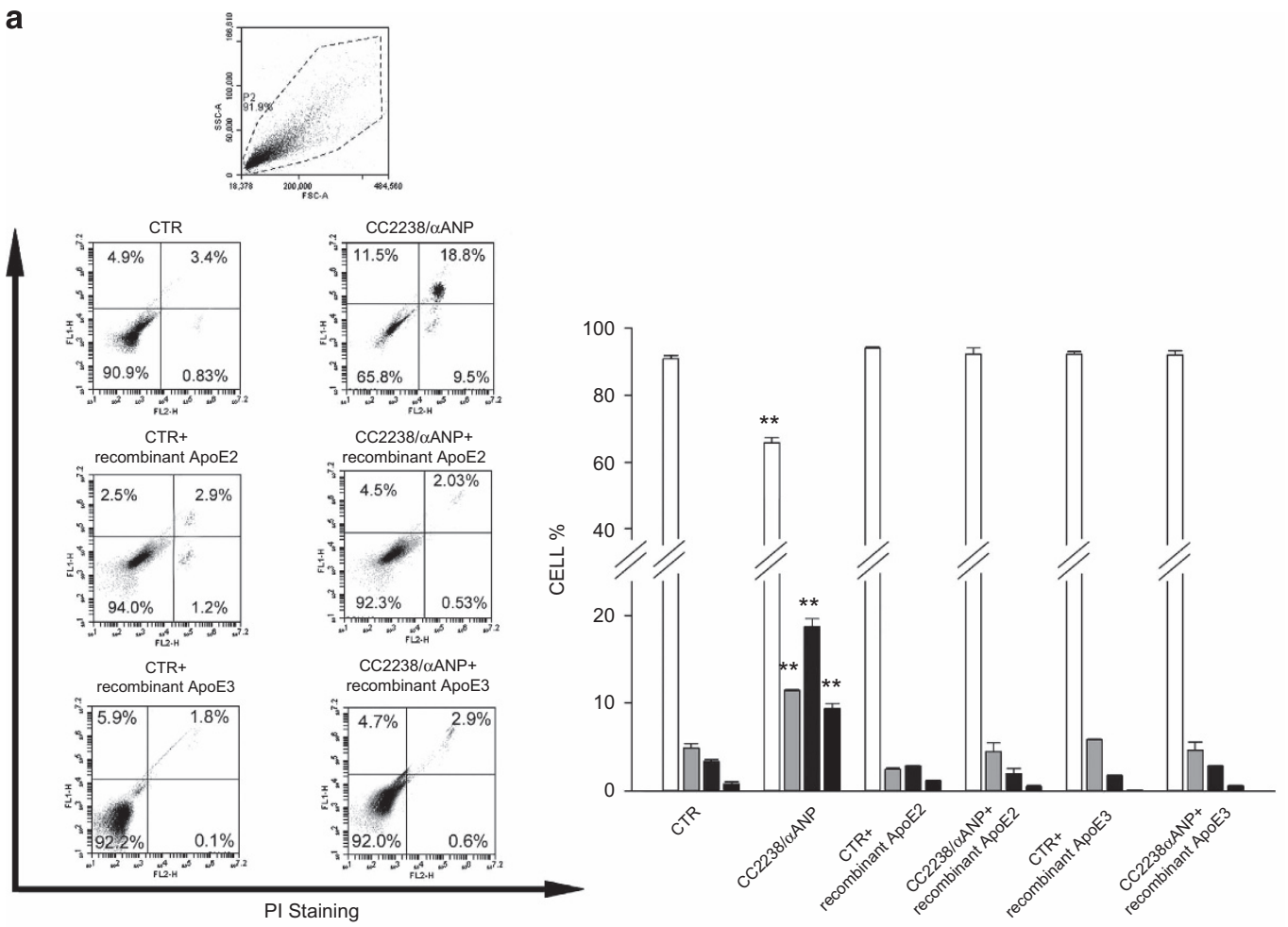

b

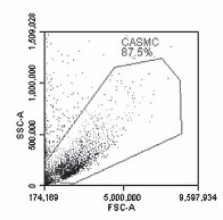

$$
\begin{aligned}
& \square \text { LIVE CELLS } \\
& \text { EARLY APOPTOTIC CELLS } \\
& \text { LATE APOPTOTIC CELLS }
\end{aligned}
$$

NECROTIC CELLS
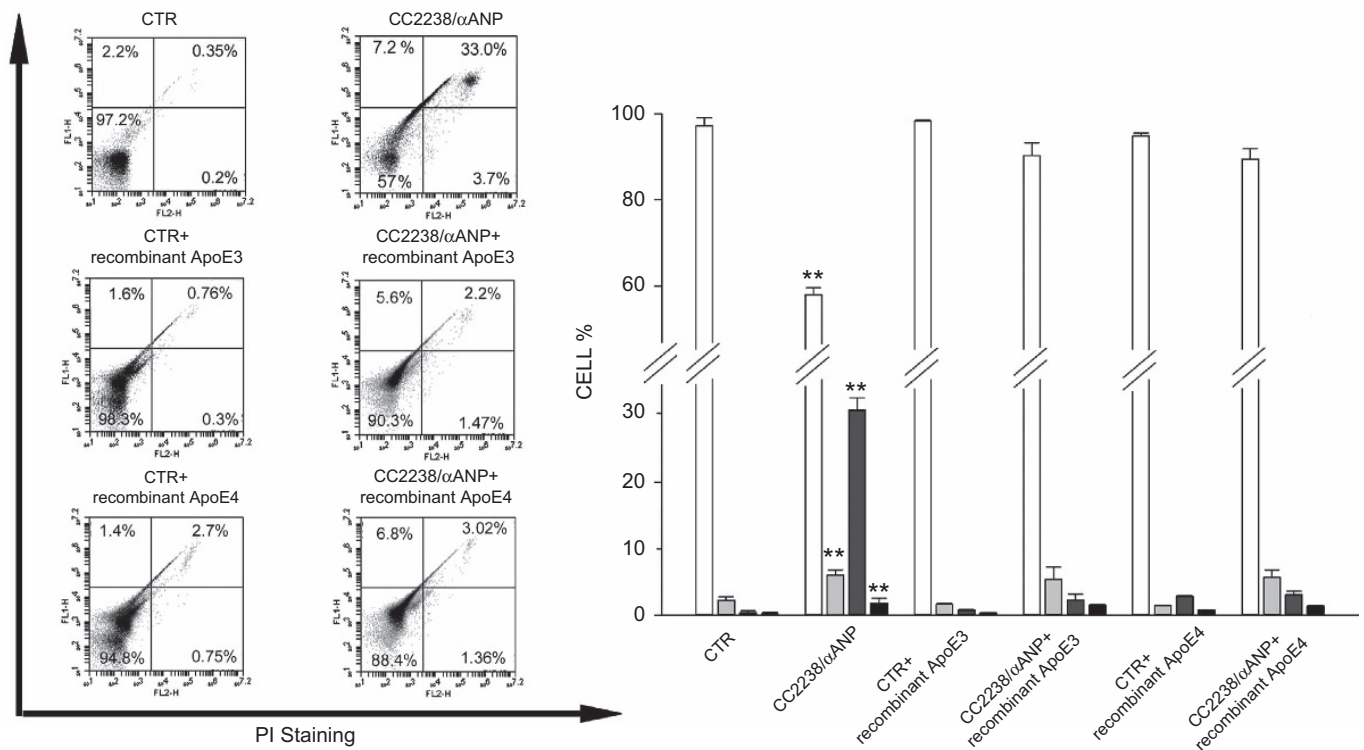

Figure 5 Effect of recombinant ApoE on cell viability in the presence of CC2238/ $\alpha$ ANP in both HUVSMCs (a) and in CASMCs (b) Cells were concomitantly exposed to recombinant ApoE and CC2238/ $\alpha$ ANP. At the end of stimulation, cell viability was analyzed by FACS. Each figure panel shows representative scatter plots for each experimental condition (left side) and corresponding densitometric analysis (right side). Results are expressed as mean \pm S.D. Number of independent experiments $=3$ for each ApoE isoform. ${ }^{*} \mathrm{P}<0.0001$ for CC2238/ $\alpha \mathrm{ANP}$ versus all other points. CC2238/ $\alpha \mathrm{ANP}$, variant $\alpha \mathrm{ANP} ; \mathrm{CTR}$, control; PI, propidium iodide; ApoE, apolipoprotein E; CTR, control 
a
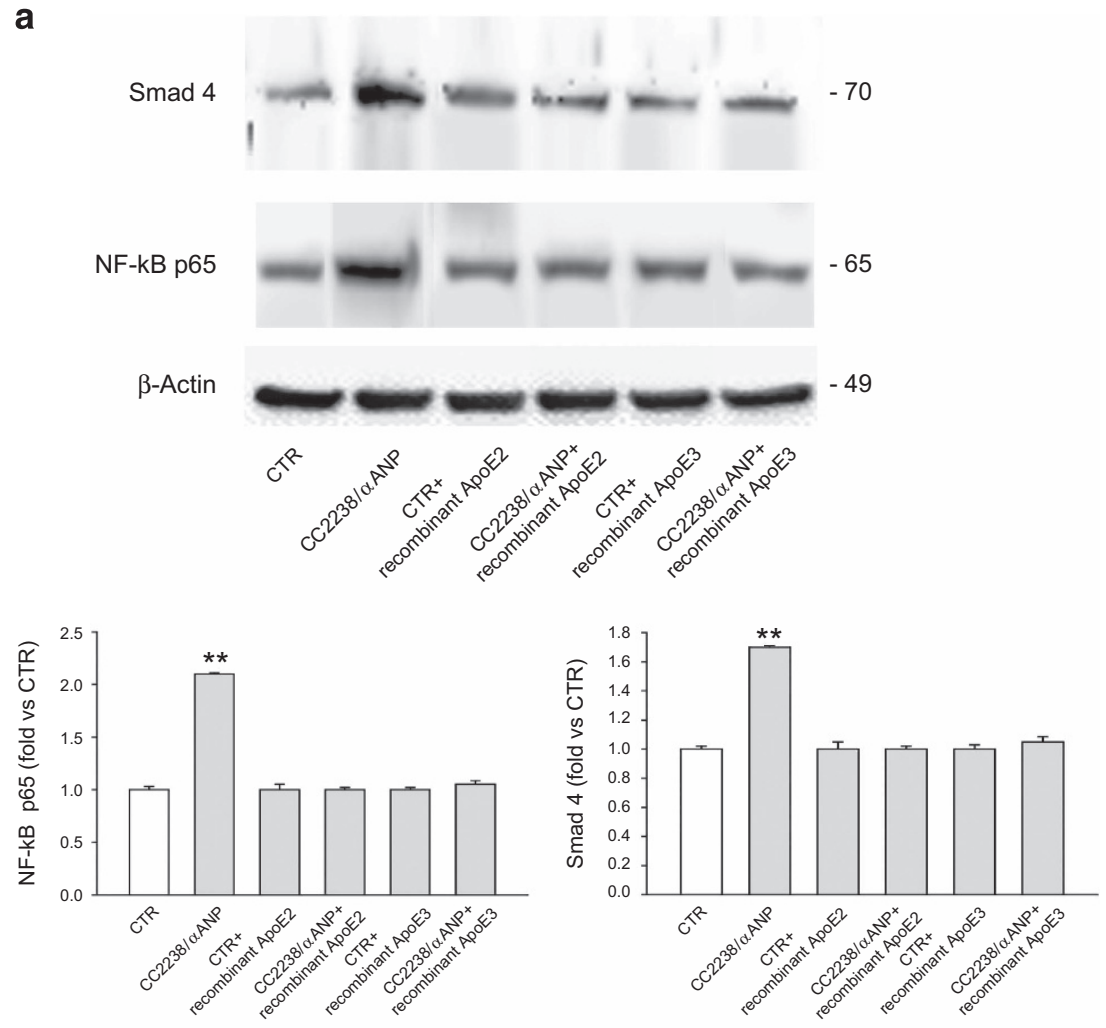

b
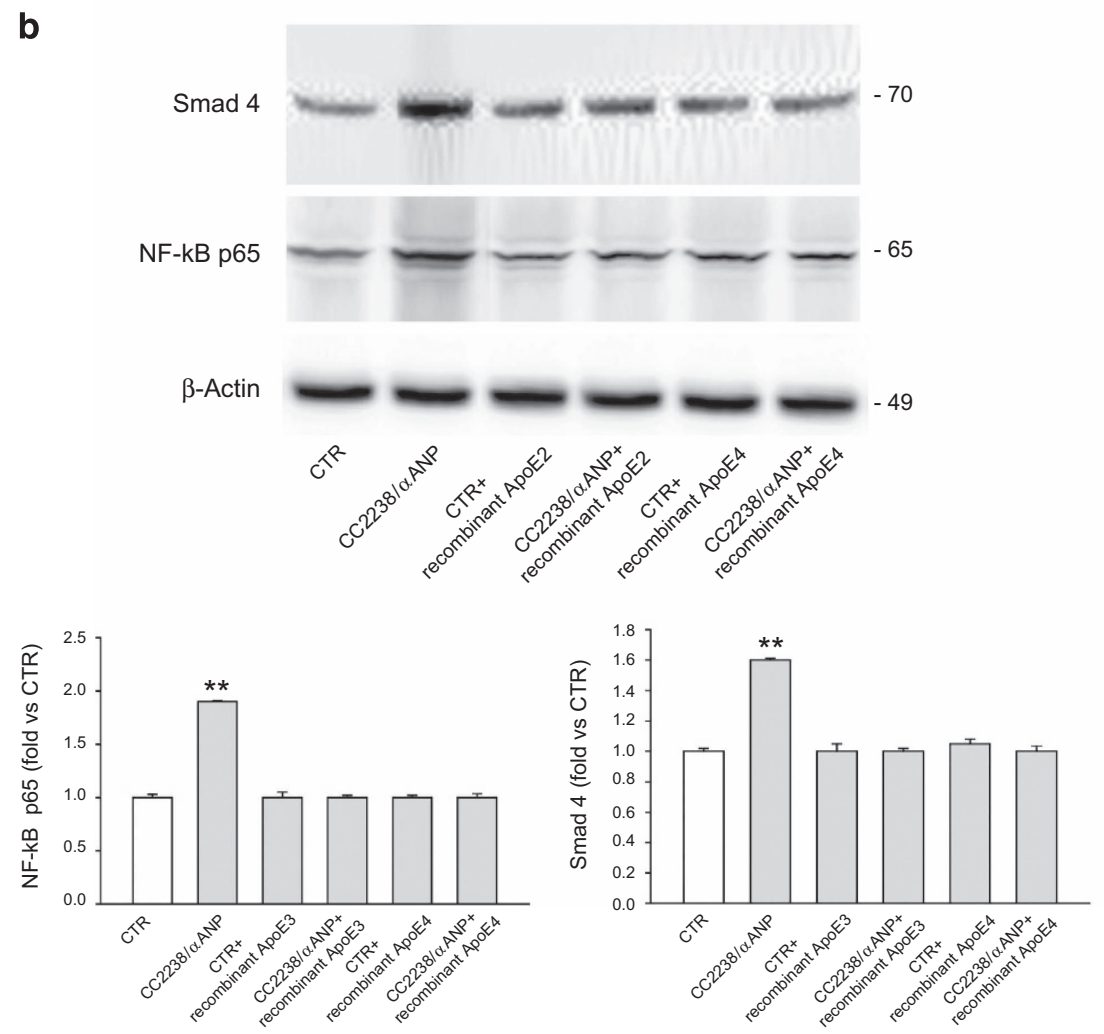

Figure 6 Effect of recombinant ApoE on markers of inflammation in the presence of CC2238/ $\alpha$ ANP in both HUVSMCs (a) and CASMCs (b). Cells were concomitantly exposed to recombinant ApoE and CC2238/ $\alpha$ ANP. Twenty-four hours after completion of stimulation, total proteins were analyzed for markers of inflammation by western blot. (a) Representative western blot of $\mathrm{Nf}-\kappa \mathrm{B}$ and Smad4, with corresponding densitometric analysis, in HUVSMCs. (b) Representative western blot of Nf- $\kappa \mathrm{B}$ and $\mathrm{Smad} 4$, with corresponding densitometric analysis, in CASMCs. Data are expressed as mean \pm S.D. Number of independent experiments $=3$ for each ApoE isoform. ${ }^{\star \star} P<0.0001$ for CC2238/ $\alpha$ ANP versus all other points. CC2238/ $\alpha$ ANP, variant $\alpha$ ANP; ApoE, apolipoprotein E; CTR, control 


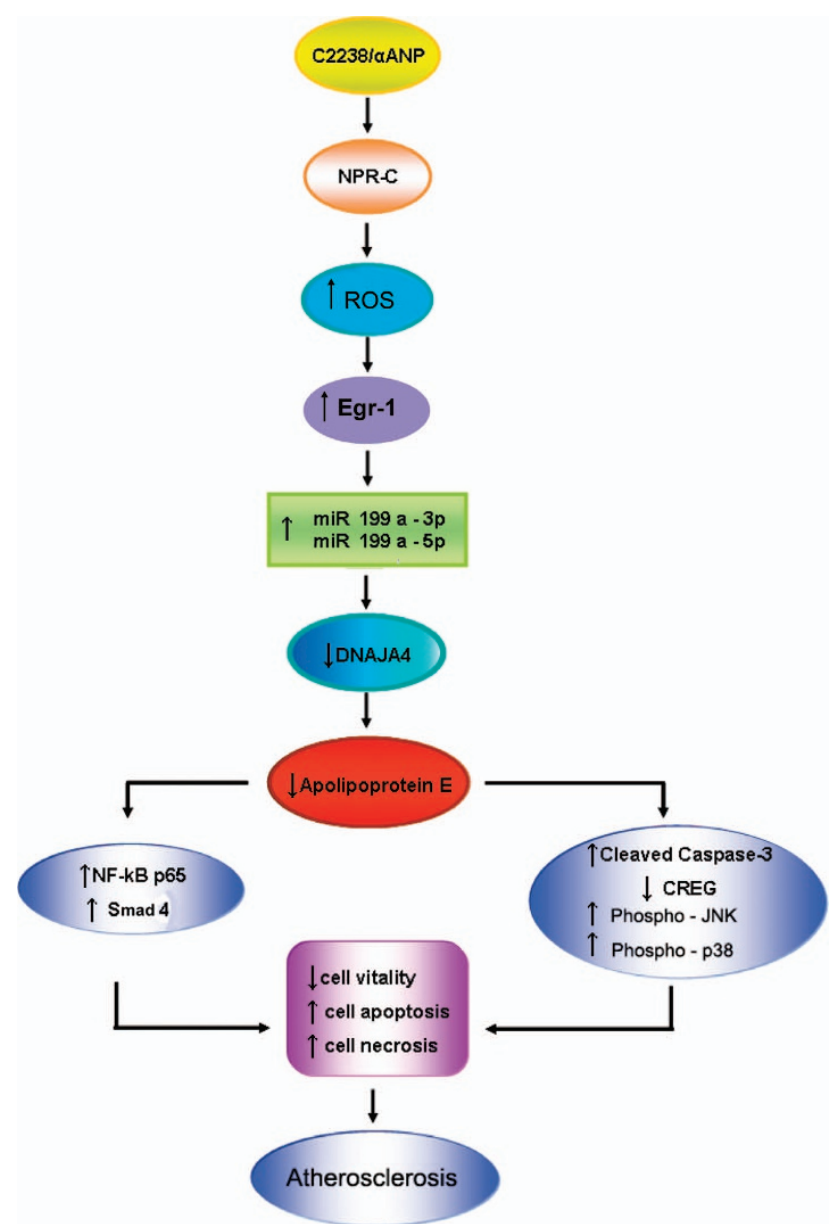

Figure 7 Schematic representation of the pathway involving NPR-C, Egr-1, miR199a-3p and miR199a-5p on ApoE modulation upon CC2238/ $\alpha$ ANP exposure in VSMCs. The positive effects of ApoE supplementation to VSMCs, despite CC2238/ $\alpha$ ANP exposure, support the strong contribution of this pathway into promotion of vascular damage through the final ApoE downregulation. C2238/ $\alpha \mathrm{ANP}$, variant $\alpha A N P$; NPR-C, type $C$ natriuretic peptide receptor; ROS, reactive oxygen species; Egr-1, early growth response protein-1; miR199a, microRNA199a; CREG, cellular repressor of E1A-stimulated gene; JNK, c-Jun N-terminal kinase

of ApoE can well explain our results, since this protein is atheroprotective not only through its lipid-lowering effect but also through antioxidant and anti-inflammatory activities. $^{19}$ The beneficial results obtained through ApoE treatment of damaged VSMCs exposed to C2238/ aANP highlight the potential key role of this molecule in the treatment of atherosclerosis in subjects with C2238/aANP variant, although several limitations still exist for its clinical application.

In summary, we report the first evidence of a novel vascular disease mechanism in VSMCs mediated by NPR-C, involving Egr-1 and two dependent small noncoding RNAs, ultimately leading to ApoE downregulation, in the presence of the C2238/aANP gene variant, an emerging cardiovascular risk factor. This newly discovered transduction cascade contributes to the wide range of damaging vascular actions due to C2238/aANP that are in contrast with the known beneficial properties of wild-type aANP. Moreover, our novel findings discover unknown pleiotropic actions of NPR-C in vascular cells through its involvement in the epigenetic regulation of vascular antiatherosclerotic proteins, such as apolipoprotein E.

\begin{abstract}
Materials and Methods
Stimulation of HUVSMCs with TT2238 and CC2238/aANP and RNA extraction for the atherosclerosis macroarray analysis. Commercially available HUVSMCs were stimulated with either synthetic wild type (TT2238) or mutant (CC2238)/ $\alpha$ ANP at a final concentration of $10^{9} \mathrm{~mol} / \mathrm{l}$ for $12 \mathrm{~h}$, as previously described. ${ }^{-11}$ Control plates received $\alpha \mathrm{ANP}$-free medium. Three experiments were performed. Total RNA, obtained at the end of stimulation, was used for CDNA synthesis and then for the macroarray analysis. Confirmation of ApoE gene and protein modulation upon CC2238/ $\alpha$ ANP and TT2238/ $\alpha$ ANP was subsequently obtained in independent experiments in HUVSMCs and also in CASMCs (number of experiments $=6$ for each cell line) by RT-PCR, based on SYBR Green methodology, and by western blotting of total proteins.
\end{abstract}

Impact of NPR-C gene silencing on modulation of ApoE gene and protein upon CC2238/aANP. HUVSMCs and CASMCs stimulation with CC2238/ $\alpha \mathrm{ANP}$ was repeated both in the presence and in the absence of NPR-C (number of experiments $=6$ ) to verify the role of this receptor in mediating the effects of CC2238/ $\alpha \mathrm{ANP}$ on ApoE gene and protein expression levels, according to our previous reports. ${ }^{10,11}$

Role of NPR-C-dependent activation of miRNA199a-3p and miRNA199a-5p in the modulation of ApoE by CC2238/aANP. Involvement of Egr-1. To verify if a known epigenetic modulation of ApoE, dependent on miRNA199a-3p and 199a-5p, ${ }^{14}$ played a role in our experimental context, total RNA, extracted from both NPR-C not silenced and silenced HUVSMCs and CASMCs, was purified to isolate small RNAs by using a commercially available kit. For RT-PCR of DNAJA4, a known target of miRNA199a, ${ }^{14}$ a TaqMan gene expression assay was used. Next, based on previous knowledge that miRNA199a expression levels are modulated by Egr-1, ${ }^{15}$ we assessed the Egr-1 protein expression level upon either TT2238/ $\alpha$ ANP or CC2238/ $\alpha$ ANP by western blotting. We also better established the role of Egr-1 into the ApoE modulation under CC2238/ $\alpha \mathrm{ANP}$ with additional experiments. First, the known role of oxidative stress on Egr-1 stimulation ${ }^{17}$ was verified by exposing VSMCs to CC2238/ $\alpha \mathrm{ANP}$ both in the absence and in the presence of apocynin (number of experiments $=3$ ), following conditions previously described. ${ }^{9}$ Egr- 1 expression levels were therefore assessed by western blotting. Subsequently, modulation of both miRNA199a-3p and miRNA199a-5p, of DNAJA4 and of ApoE was determined in Egr-1 silenced VSMCs exposed to CC2238/ $\alpha$ ANP (number of experiments $=4$ ).

Assessment of cleaved caspase-3, CREG, JNK, p38MAPK, Nf$k B$ p65 and TGF $\beta$ (Smad4) expression levels as markers of apoptosis, necrosis and inflammation upon CC2238/aANP both in the presence and in the absence of NPR-C. To verify whether downregulation of ApoE expression in our experimental conditions was associated, as expected, to increased rate of apoptosis, necrosis and inflammation, ${ }^{13}$ total proteins were analyzed by using the following specific primary antibodies: anti-cleaved caspase-3, anti-CREG, anti-phosphoJNK, anti-JNK, anti-phosphop38MAPK, anti-p38MAPK, anti-NF $\kappa_{\kappa} B$ 65, anti-Smad4, anti- $\beta$-actin. The latter was used as the housekeeping protein. Following incubation with horseradish peroxidase-conjugated secondary antibody, signals were revealed as described below.

Impact of exposure to recombinant ApoE on cell viability, apoptosis, necrosis and inflammation in both HUVSMCs and CASMCs in the presence of CC2238/aANP. To test the ability of ApoE supplementation to rescue the harmful effects induced by CC2238/ $\alpha A N P$, and based on sequencing results of specific ApoE isoforms expressed in the two cell lines, HUVSMCs were exposed for $12 \mathrm{~h}$ to CC2238/ $\mathrm{ANP}$ and either recombinant ApoE2 or ApoE3 protein (10 $\mu \mathrm{g} / \mathrm{ml}$; Sigma). CAMSCs were exposed to CC2238/ $\alpha \mathrm{ANP}$ and either recombinant ApoE3 or ApoE4 protein $(10 \mu \mathrm{g} / \mathrm{ml}$; Sigma). Recombinant proteins for ApoE were added to VSMCs as previously described. ${ }^{37}$ 
Twenty-four hours after completion of exposure to CC2238/ $\alpha$ ANP and the specific recombinant $A p o E$ isoform, counting of apoptotic cells was performed by flow cytometry analysis (FACS) and total proteins were extracted for western blotting analysis of $\mathrm{Nf}-\kappa \mathrm{Bp} 65$ and Smad4.

Experiments were performed in triplicate for each ApoE isoform.

Cells culture. Commercially available HUVSMCs, purchased from ATCC (American Type Culture Collection; Manassas, VA, USA), were grown in Kaighn's F12 medium containing $2 \mathrm{mM}$ L-glutamine, $1.5 \mathrm{~g} / \mathrm{l}$ sodium bicarbonate, and supplemented with $0.1 \mathrm{mg} / \mathrm{ml}$ heparin, $0.03 \mathrm{mg} / \mathrm{ml}$ endothelial cell growth supplement, $10 \%$ fetal bovine serum. Commercially available CASMCs (purchased from Lonza, Walkersville, MD, USA) were grown in Smooth Muscle Growth Medium2 (SmgM-2; Lonza). Four batches were used for each cell line to perform all experiments.

Cells were used within the fifth passage and at $70 \%$ confluence. For stimulation with either TT2238 or CC2238/ $\alpha$ ANP, they were seeded in 24-well plates $\left(8 \times 10^{4}\right.$ cells/well), cultured in their respective growth medium for $24 \mathrm{~h}$, subsequently starved and stimulated with $\alpha \mathrm{ANP}$ at a final concentration of $10^{9} \mathrm{~mol} / \mathrm{l}$ for $12 \mathrm{~h}$ in the presence of $10 \%$ fetal calf serum. Control plates received $\alpha$ ANP-free medium.

Total RNA extraction. Total RNA was obtained using Trizol reagen (Life Technologies, Carlsbad, CA, USA), subjected to DNAse I treatment (Qiagen, Venlo, Netherlands) and subsequently purified using RNeasy Mini Kit (Qiagen) according to the manufacturer's instructions. RNA integrity was assessed by denaturing agarose gel electrophoresis and its concentration was verified by using NanoDrop2000c UV-Vis spectrophotometer (Thermo Scientific, Waltham, MA USA).

RT-PCR macroarray analysis. Three experiments were carried out with each stimulus and RNA was pooled for the macroarray analysis. Two micrograms of total RNA were used for cDNA synthesis using $\mathrm{RT}^{2}$ First Strand Kit (Qiagen). We carried out quantitative RT-PCR macroarray analysis using a Human Atherosclerosis $\mathrm{RT}^{2}$ Profiler PCR Array purchased from Qiagen. Experiments were performed as previously described. ${ }^{9}$ Briefly, cDNA template was mixed with one of ready to use $\mathrm{RT}^{2}$ Real-Time SYBR Green PCR Master Mix (Qiagen). The chosen array contains a panel of 84 primer sets for pathway-focused genes (human atherosclerosis), five housekeeping genes and three RNA and PCR quality controls. The mixture was aliquoted into each well of the same plate containing predispensed gene-specific primer sets and PCR was performed on ViiA 7 Real-Time PCR System (Life Technologies). Experiments were performed in triplicate. Data analysis was carried out using the PCR Array Data Analysis Web Portal (http://www. superarray.-com/pcrarraydataanalysis.php) and $\Delta \Delta \mathrm{Ct}$ method. ${ }^{38}$ Results were expressed as relative levels of each gene mRNA under the effect of either CC2238 or TT2238/ $\alpha$ ANP referred to the expression of this gene in unstimulated cells (that were chosen to represent $1 \mathrm{x}$ expression of each gene). Results were considered significant when mRNA expression was 5-fold higher or lower than that of unstimulated cells.

Quantitative RT-PCR of ApoE, NPR-C, Egr-1 (SYBR Green methodology). Two microliters of CDNA were mixed with $5 \mu$ l of SYBR Green PCR master Mix (Life Technologies) and $0.5 \mu$ of specific primers: ApoE (forward 5'-GAGCAAGCGGTGGAGACAG-3' and reverse 5'-CATCAGCGCCCTCAGTTCC -3'); NPR-C (forward 5'-GGAAGACATCGTGCGCAATA-3' and reverse 5'-GATGCT CCGGATGGTGTCA-3'); Egr-1 (forward 5'-ACCGCAGAGTCTTTTCCTGACA-3' and reverse $5^{\prime}$-GGTGCAGGCTCCAGGGAAAA-3').

$\beta$-Actin was used as the housekeeping gene (forward $5^{\prime}$-GCAAGAGATGGC CACGGCTG-3' and reverse 5'-CCACAGGACTCCATGCCCAG-3'). RT-PCR was carried out on the ViiA 7 Real-Time PCR System with cycling conditions of $50^{\circ} \mathrm{C}$ for $2 \mathrm{~min}, 95^{\circ} \mathrm{C}$ for $10 \mathrm{~min}$ followed by $95^{\circ} \mathrm{C}$ for $15 \mathrm{~s}$ and $60^{\circ} \mathrm{C}$ for $60 \mathrm{~s}$ for a total of 40 cycles. Measurements were performed in triplicate in each assay. Results were expressed as relative levels of each gene mRNA as compared with control cells.

Quantitative RT-PCR of miRNA199a-3p, miRNA199a-5p, DNAJA4 (TaqMan methodology). Total RNA was purified to isolate small RNAs with a specific kit (miRNeasy Mini Kit; Qiagen) according to the manufacturer's instructions. For cDNA synthesis of miR199a-3p, miR199a-5p and control miRU87, $1 \mu \mathrm{g}$ of purified RNA was mixed with $3 \mu \mathrm{l}$ of NCode VILO miRNA CDNA Synthesis Kit (Life Technologies) and $1 \times$ RT-primer (Life Technologies) in a total reaction volume of $20 \mu \mathrm{l}$. Reaction was incubated at $16{ }^{\circ} \mathrm{C}$ for $30 \mathrm{~min}, 42^{\circ} \mathrm{C}$ for $30 \mathrm{~min}$ and $85^{\circ} \mathrm{C}$ for 5 min in a T-100 Thermal Cycler (Bio-Rad, Hercules, CA, USA). Then, $2 \mu \mathrm{l}$ of the RT reaction was added to $1 \mu \mathrm{l}$ of a specific TaqMan MicroRNA Assay $20 \mathrm{x}$ (miR199a-3p, miR199a-5p, miRU87; Life Technologies) and $10 \mu \mathrm{l}$ of TaqMan Universal PCR Master Mix II with UNG (Life Technologies) in a $20 \mu l$ final volume. RT-PCR was performed using the ViiA 7 Real-Time PCR System with cycling conditions of $95^{\circ} \mathrm{C}$ for $10 \mathrm{~min}$ followed by $95^{\circ} \mathrm{C}$ for $15 \mathrm{~s}$ and $60^{\circ} \mathrm{C}$ for $60 \mathrm{~s}$ for a total of 40 cycles. Each TaqMan assay was run in triplicate. Results were expressed as relative levels of each miRNA under the effect of different treatments relative to unstimulated cells.

For RT-PCR of DNAJA4, $2 \mu \mathrm{l}$ of CDNA were mixed with $10 \mu \mathrm{l}$ of TaqMan Universal Master Mix II with UNG and $1 \mu$ of DNAJA4 TaqMan Gene Expression Assay (Life Technologies) in a $20 \mu$ linal volume. $\beta$-Actin was used as the housekeeping gene. RT-PCR was performed using ViiA 7 Real-Time PCR System with cycling conditions of $50^{\circ} \mathrm{C}$ for $2 \mathrm{~min}, 95^{\circ} \mathrm{C}$ for $10 \mathrm{~min}$ followed by $95^{\circ} \mathrm{C}$ for $15 \mathrm{~s}$ and $60{ }^{\circ} \mathrm{C}$ for $60 \mathrm{~s}$ for a total of 40 cycles. Each assay was run in triplicate. Results were expressed as mRNA levels under the effect of different treatments relative to unstimulated cells.

Total proteins extraction and western blotting. Total proteins were extracted from cells $24 \mathrm{~h}$ after completion of either TT2238/ $\alpha$ ANP or CC2238/ $\alpha$ ANP exposure. Samples were lysed in $1: 10$ weight/volume in lysis buffer $(50 \mathrm{mM} \mathrm{NaCl}$, $100 \mathrm{mM}$ Tris-HCl pH 7.4, $1 \mathrm{mM}$ ethylenediaminetetracetic acid (EDTA), 1\% SDS) supplemented with protease and phosphatase inhibitors (Sigma Aldrich, Saint Louis, MO, USA), incubated on ice for $15 \mathrm{~min}$. and centrifuged at $13000 \mathrm{r}$. p.m. for $15 \mathrm{~min}$. Protein concentration was determined by DC Protein Assay Kit (Bio-Rad) following the manufacturer's instructions. Protein lysates were boiled at $95^{\circ} \mathrm{C}$ for $5 \mathrm{~min}$ in the presence of gel loading buffer (Bio-Rad). Fifty micrograms of each sample were loaded on 10\% SDS-polyacrylamide gel and run for $120 \mathrm{~min}$ at $100 \mathrm{~V}$. Proteins were then transferred onto polyvinylidene difluoride membranes (PVDF; Bio-Rad) using the Trans-Blot Turbo Transfer System (Bio-Rad). Nonspecific binding sites were blocked at room temperature for $1 \mathrm{~h}$ in $5 \%$ bovine serum albumin in Tris-buffered saline buffer with $0.1 \%$ Tween 20 (Sigma) (TBS-T). Membranes were incubated at $4{ }^{\circ} \mathrm{C}$ overnight with the following primary antibodies:

anti-ApoE (1:1000; Millipore, Temecula, CA, USA), anti-Egr-1 (1:1000; Cell Signaling, Danvers, MA, USA), anti-phosphoJNK (1:200; Santa Cruz Laboratories, Santa Cruz, CA, USA), anti-JNK (1:200; Santa Cruz), anti-phospho-p38MAPK ( 1 : 200; Santa Cruz), anti-p38MAPK (1 : 200; Santa Cruz), anti-NFKBp65 (1 : 200; Santa Cruz), anti-cleaved caspase-3 (1: 1000; Cell Signaling), anti-Smad4 (1:1000; Cell Signaling); anti-CREG (1:1000; R\&D System, Minneapolis, MN, USA), anti- $\beta$-actin (1: 1000; Santa Cruz).

Following three washes of $10 \mathrm{~min}$ in TBS-T, membranes were incubated for $1 \mathrm{~h}$ at room temperature with $1: 5000$ horseradish peroxidase-conjugated donkey anti-goat (for ApoE) or goat anti-mouse or goat anti-rabbit secondary antibodies diluted in TBS-T. After three washes of $10 \mathrm{~min}$ in TBS-T, signals were revealed with an enhanced chemiluminescence detection system (Luminata Crescendo; Millipore, Darmstadt, Germany) and the immunoreactivity of bands was visualized using ChemiDoc XRS+Imaging System (Bio-Rad). Protein bands were scanned and quantified densitometrically. They were finally normalized using $\beta$-actin levels.

NPR-C and Egr-1 gene silencing. NPR-C and Egr-1 gene silencing was performed with specific siRNAs (Mission siRNA; Sigma) by following conditions previously described. ${ }^{10,11}$ Twenty-four hours after transfection, both silenced and not silenced cells were exposed to CC2238/ $\alpha \mathrm{ANP}$ for $12 \mathrm{~h}$ and subsequently extracted for total RNA and total proteins. Efficiency of gene silencing was assessed by RT-PCR, following conditions described above.

Role of oxidative stress in the Egr-1 induced increase by CC2238/aANP. The known role of oxidative stress on Egr-1 stimulation ${ }^{17}$ was verified by exposing VSMCs to CC2238/ $\alpha$ ANP both in the absence and in the presence of apocynin, following conditions previously described. ${ }^{9}$ Egr-1 expression levels were therefore assessed by western blotting.

Sequencing of apoE gene expressed in HUVSMCs and CASMCs. Genomic DNA was isolated from both HUVSMCs and CASMCs using a commercially available kit (Qiagen, Chicago, IL, USA). In order to identify the three allelic forms of human ApoE gene (allele $\varepsilon 2, \varepsilon 3, \varepsilon 4$ ) PCR reactions were set up by using a specific pair of primers: forward 5'-CTCCCACTGTGCGACACC-3', 
reverse $5^{\prime}$-CTGCTCCTTCACCTCGTCC-3'. DNA was first amplified by PCR with 40 cycles at an annealing temperature of $55^{\circ} \mathrm{C}$ using a T-100 Thermal Cycler (Bio-Rad). Following purification of the PCR product (562 bp) with MinElute PCR purification kit (Qiagen), sequence reactions were prepared using the Big Dye Terminator v3.1 cycle sequencing Kit (Applied Biosystems, Carlsbad, CA, USA). Unincorporated dye terminators from sequencing reactions were removed using DyeEx 2.0 Spin kit (Qiagen). Purified fragments were electrophoresed on an $\mathrm{ABI}$ PRISM 3100 Genetic Analyzer (Applied Biosystems) according to the manufacturer's protocol. All sequencing results were compared with those present in the NCBI databases using BLAST to confirm the allelic variants.

Flow-cytometry analysis. Twenty-four hours after completion of exposure to CC2238/ $\alpha \mathrm{ANP}$ and the specific recombinant ApoE isoform, counting of apoptotic cells was performed by FACS using Annexin V-Fitc and propidium iodide (PI) staining (ImmunoStep, Salamanca, Spain). For this purpose, cells were harvested by incubation with $1 \mathrm{ml}$ of trypsin/EDTA (Lonza) for $3 \mathrm{~min}$ at $37^{\circ} \mathrm{C}$. Trypsinization was stopped by addition of medium and the suspension was centrifuged at 1200 r.p.m. for $5 \mathrm{~min}$ at $4{ }^{\circ} \mathrm{C}$. Each pellet was washed with cold phosphate-buffered saline (PBS $1 \mathrm{x}$ ). Then, tubes were vortexed thoroughly and centrifuged again as before. Cells were gently resuspended and vortexed in binding buffer at a concentration of $3 \times 10^{6}$ cells $/ \mathrm{ml}$. Then, $100 \mu \mathrm{l}$ of cell suspension was added to $5 \mu \mathrm{l}$ of Annexin $\mathrm{V}$ and $10 \mu \mathrm{l}$ of PI. Samples were mixed for $15 \mathrm{~min}$ in the dark at $4{ }^{\circ} \mathrm{C}$ and $400 \mu \mathrm{l}$ of PBS $1 \mathrm{x}$ was added to the solution. Ten thousand cells were analyzed by FACS on a BD Accuri C6 flow cytometer (Biosciences, Erembodegem-Dorp, Belgium) to count apoptotic cells. Both negative control (untreated cells) and positive control (cells treated with hydrogen peroxide) were included in the analysis.

Statistical analysis. Continuous variables are expressed as mean \pm S.D. Comparisons between two groups were performed using Student's $t$-test. When the analysis was adjusted for the multiplicity of compared groups, one-way ANOVA followed by Bonferroni post hoc test was performed. Normality of variables distribution was tested by the Kolmogorov-Smirnov test. GraphPad Software (San Diego, CA, USA; version 5.0) and SPSS statistical software (SPSS Inc., Chicago, IL, USA; version 12.0) were used for statistical analysis. $P<0.05$ was considered significant.

\section{Conflict of Interest}

The authors declare no conflict of interest.

Acknowledgements. The present work was supported by a grant (Ricerca Corrente) from the Italian Ministry of Health to MV and SR; by the 5\%o grant to MV and SR.

1. Volpe M, Rubattu S, Burnett J Jr. Natriuretic peptides in cardiovascular diseases: current use and perspectives. Eur Heart J 2014; 35: 419-425.

2. Gruchala M, Ciecwierz D, Wasag B, Targoński R, Dubaniewicz W, Nowak A et al. Association of the Scal atrial natriuretic peptide gene polymorphism with nonfatal myocardial infarction and extent of coronary artery disease. Am Heart J 2003; 145: 125-131.

3. Rubattu S, Stanzione R, Di Angelantonio E, Zanda B, Evangelista A, Tarasi D et al. Atrial natriuretic peptide gene polymorphisms and the risk of ischemic stroke in humans. Stroke 2004; 35: 814-818.

4. Barbato E, Bartunek J, Mangiacapra F, Sciarretta S, Stanzione R, Delrue L et al. Influence of rs5065 atrial natriuretic peptide gene variant on coronary artery disease. J Am Coll Cardiol 2012; 59: 1763-1770.

5. Cannone V, Huntley BK, Olson TM, Heublein DM, Scott CG, Bailey KR et al. Atrial natriuretic peptide gene variant rs5065 and risk for cardiovascular disease in the general community: a 9-year follow-up study. Hypertension 2013; 62: 860-865.

6. Ziaee S, Kalayinia S, Boroumand MA, Pourgholi L, Cheraghi S, Anvari MS et al. Association between the atrial natriuretic peptide rs5065 gene polymorphism and the presence and severity of coronary artery disease in an Iranian population. Coron Artery Dis 2014; 25: 242-246.

7. Rubattu S, De Giusti M, Farcomeni A, Abbolito S, Comito F, Cangianiello S et al. T2238C ANP gene variant and risk of recurrent acute coronary syndromes in an Italian cohort of ischemic heart disease patients. J Cardiovasc Med 2016 (in press).

8. Xing DG, Zhang DY, Wang ZF, Ding DL, Wang J, Wang JY. Correlations of ANP genetic polymorphisms and serum levels with ischemic stroke risk: a meta-analysis. Genet Test $\mathrm{Mol}$ Biomarkers 2014; 18: 349-356.
9. Scarpino S, Marchitti S, Stanzione R, Evangelista A, Di Castro S, Savoia C et al. ROSmediated differential effects of the human atrial natriuretic peptide T2238C genetic variant on endothelial cells in vitro. J Hypertens 2009; 27: 1804-1813.

10. Sciarretta S, Marchitti S, Bianchi F, Moyes A, Barbato E, Di Castro S et al. The C2238 atrial natriuretic peptide molecular variant is associated with endothelial damage and dysfunction through natriuretic peptide receptor C signaling. Circ Res 2013; 112: 1355-1364.

11. Rubattu S, Marchitti S, Bianchi F, Di Castro S, Stanzione R, Cotugno M et al. The C2238/ $\alpha \mathrm{ANP}$ variant is a negative modulator of both viability and function of coronary artery smooth muscle cells. PLOs One 2014; 9: e113108.

12. Ip JH, Fuster V, Badimon L, Badimon J, Taubman MB, Chesebro JH. Syndromes of accelerated atherosclerosis: role of vascular injury and smooth muscle cell proliferation. J Am Coll Cardiol. 1990; 15: 1667-1687.

13. Pendse AA, Arbones-Mainar JM, Johnson LA, Altenburg MK, Maeda N. Apolipoprotein E knock-out and knock-in mice: atherosclerosis, metabolic syndrome, and beyond. J Lipid Res 2009; 50: S178-S182.

14. Pencheva N, Tran H, Buss $\mathrm{C}$, Huh D, Drobnjak M, Busam K et al. Convergent multi-miRNA targeting of ApoE drives LRP1/LRP8-dependent melanoma metastasis and angiogenesis. Cell 2012; 151: 1068-1082.

15. Sakurai K, Furukawa C, Haraguchi T, Inada K, Shiogama K, Tagawa $T$ et al. MicroRNAs miR-199a-5p and -3p target the BRM subunit of SWI/SNF to generate a double-negative feedback loop in a variety of human cancers. Cancer Res 2011; 71: 1680-1689.

16. McCaffrey TA, Fu C, Du B, Eksinar S, Kent KC, Bush H Jr et al. High level expression of Egr-1 and Egr-1 inducible genes in mouse and human atherosclerosis. J Clin Invest 2000; 105: 653-662.

17. Hasan RN, Schafer Al. Hemin upregulates Egr-1 expression in vascular smooth muscle cells via reactive oxygen species ERK-1/2 - Elk-1 and NF-kB. Circ Res 2008; 102 : $42-50$.

18. Han Y, Wu G, Deng J, Tao J, Guo L, Tian X et al. Cellular repressor of E1A-stimulated genes inhibits human vascular smooth muscle cell apoptosis via blocking P38/JNK MAP kinase activation. J Mol Cell Cardiol 2010; 48: 1225-1235.

19. Breslow JL. Mouse models of atherosclerosis. Science 1996; 272: 685-688.

20. Mahley RW, Rall SC Jr. Apolipoprotein E: far more than a lipid transport protein. Annu Rev Genomics Hum Genet 2000; 1: 507-537.

21. Beattie JH, Duthie SJ, Kwun I, Ha T, Gordon MJ. Rapid quantification of aortic lesions in ApoE $^{-/-}$mice. J Vasc Res 2009; 46: 347-352.

22. Rodriguez-Vita J, Sanchez-Galan E, Santamaria B, Sanchez-Lopez E, Rodrigues-Diez R, Blanco-Colio LM et al. Essential role of TGF- $\beta /$ Smad pathway on statin dependent vascular smooth muscle cell regulation. PLoS One 2008; 3: e3959.

23. Zhang T, Dai $P$, Cheng D, Zhang L, Chen Z, Meng X et al. Obesity occurring in apolipoprotein E-knockout mice has mild effects on fertility. Reproduction 2013; 147: 141-151.

24. Baitsch D, Bock HH, Engel T, Telgmann R, Müller-Tidow C, Varga G et al. Apolipoprotein E induces antiinflammatory phenotype in macrophages. Arterioscler Thromb Vasc Biol 2011; 31: $1160-1168$.

25. Ward H, Mitrou PN, Bowman R, Luben R, Wareham NJ, Khaw KT et al. APOE genotype, lipids, and coronary heart disease risk: a prospective population study. Arch Intern Med 2009; 169: 1424-1429.

26. Mahley RW, Weisgraber KH, Huang Y. Apolipoprotein E4: a causative factor and therapeutic target in neuropathology, including Alzheimer's disease. Proc Natl Acad Sci USA 2006; 103 5644-5651.

27. Greig FH, Hutchison L, Spickett CM, Kennedy S. Differential effects of chlorinated and oxidized phospholipids in vascular tissue: implications for neointima formation. Clin Sci2015; 128: $579-592$.

28. Casco VH, Veinot JP, Kuroski de Bold MLK, Masters RG, Stevenson MM, de Bold AJ. Natriuretic peptide system gene expression in human coronary arteries. $\mathrm{J}$ Histochem Cytochem 2002; 50: 799-809.

29. Arnal JF, Castano C, Maupas E, Mugniot A, Darblade B, Gourdy P et al. Omapatrilat, a dual angiotensin-converting enzyme and neutral endopeptidase inhibitor, prevents fatty streak deposit in apolipoprotein E-deficient mice. Atherosclerosis 2001; 155: 291-295.

30. Barbato E, Rubattu S, Bartunek J, Berni A, Sarno G, Vanderheyden M et al. Role of cardiac natriuretic peptides in human coronary atherosclerosis. Atherosclerosis 2009; 206: 258-264.

31. Alexander MR, Knowles JW, Nishikimi T, Maeda N. Increased atherosclerosis and smooth muscle cell hypertrophy in natriuretic peptide receptor $\mathrm{A}^{-/-}$Apolipoprotein $\mathrm{E}^{-1-}$ mice. Arterioscler Thromb Vasc Biol 2003; 23: 1077-1082.

32. Harja E, Bucciarelli LG, Lu Y, Stern DM, Zou YS, Schmidt AM et al. Early growth response-1 promotes atherogenesis. Mice deficient in early growth response-1 and Apolipoprotein E display decreased atherosclerosis and vascular inflammation. Circ Res 2004; 94: 333-339.

33. laconetti C, De Rosa S, Polimeni A, Sorrentino S, Gareri C, Carino A et al. Down-regulation of miR23b induces phenotypic switching of vascular smooth muscle cells in vitro and in vivo. Cardiovasc Res 2015; 107: 522-533.

34. Evans V, Foster H, Graham IR, Foster K, Athanasopoulos T, Simons JP et al. Human apolipoprotein $\mathrm{E}$ expression from mouse skeletal muscle by elecrotransfer of nonviral DNA 
(plasmid) and pseudotyped recombinant adeno-associated virus (AAV2/7). Hum Gene Ther 2008; 19: 569-578.

35. White CR, Garber DW, Anantharamaiah GM. Anti-inflammatory and cholesterol-reducing properties of apolipoprotein mimetics: a review. J Lipid Res 2014; 55: 2007-2021.

36. Cioffi L, Sturtz FG, Wittmer S, Barut B, Smith-Gbur J, Moore V et al. A novel endothelial cell-based gene therapy platform for the in vivo delivery of apolipoprotein E. Gene Ther 1999; 6: 1153-1159.

37. Zeleny M, Swertfeger DK, Weisgraber KH, Hui DY. Distinct apolipoprotein E isoform preference for inhibition of smooth muscle cell migration and proliferation. Biochemistry 2002; 41: 11820-11823

38. Livak KJ, Schmittgen TD. Analysis of relative gene expression data using real-time quantitative PCR and the 2(-Delta Delta C(T)) method. Methods 2001; 25: 402-408. (c) (i) Cell Death and Disease is an open-access journal published by Nature Publishing Group. This work is licensed under a Creative Commons Attribution 4.0 International License. The images or other third party material in this article are included in the article's Creative Commons license, unless indicated otherwise in the credit line; if the material is not included under the Creative Commons license, users will need to obtain permission from the license holder to reproduce the material. To view a copy of this license, visit http://creativecommons.org/licenses/by/4.0/

Supplementary Information accompanies this paper on Cell Death and Disease website (http://www.nature.com/cddis) 